\title{
Cleaner Nudges? Policy Labels and Investment Decision-making
}

\author{
Ian Lange ${ }^{* a}$, Mirko Moro ${ }^{\mathrm{b}}$, and Mohammad Mahbubur Rahman ${ }^{\mathrm{c}}$ \\ ${ }^{\mathrm{a}}$ Division of Economics \& Business, Colorado School of Mines, Golden, CO, USA, 80403 \\ ${ }^{\mathrm{b}}$ Division of Economics, University of Stirling, Scotland, UK, FK9 4LA \\ ${ }^{\mathrm{c}}$ School of Health Sciences and Social Work, University of Portsmouth, Portsmouth, UK, POI \\ $2 D T$
}

April 2018

\footnotetext{
${ }^{*}$ Corresponding author: E-mail address: ilange@mines.edu. The authors titles are Assistant Professor, Senior Lecturer, and Senior Research Associate, respectively. This work was funded by an Open Door grant (OPD/41068) from the Nuffield Foundation. The Nuffield Foundation had no role in the design, conduct, analysis or reporting of the study. The views expressed here do not necessarily reflect those of the Nuffield Foundation. The authors wish to thank Chris Timmins, Natalia Montinari, Dan Kaffine, Jay Shimshack, Harrison Fell, Susana Ferreira, Greg Colson, and Rabeya Khatoon, participants at seminars at Edinburgh University, Durham University, Stirling University, Colorado School of Mines, Colorado State University, University of Georgia, University of the Balearic Islands, Midwest Economic Association Conference 2014 and Royal Economic Society Conference 2014 for helpful comments and suggestions.
} 


\begin{abstract}
Recent evidence suggests that labeling of unconditional cash transfers leads recipients to spend more on the labeled good. In this paper we show that the Winter Fuel Payment, an unconditional cash transfer, has distortionary effects on the market for goods related to the labeled product, renewable technologies. Using a Regression Discontinuity Design this analysis finds a robust reduction in the probability to install renewable energy technologies of 1.2 percentage points. Falsification tests support the labeling hypothesis. As a result, households use too much energy from sources which generate pollution and too little from relatively cleaner technologies.
\end{abstract}

JEL Classification: C31, Q42, Q48

Key words: Winter Fuel Payment; Regression Discontinuity; Renewable energy 


\section{Introduction}

Many governments have started to incorporate the lessons of behavioral economics in their policies. These behavioral interventions (or "nudges") are characterized by their non-pecuniary nature, including appeals to social norms, information provision, default options, and cash transfer labels (e.g., Schultz et al., 2007; Homonoff, 2013; Allcott, 2011; Allcott and Mullainathan, 2010; Ferraro and Price, 2013). The attractiveness of these interventions lies in the fact that they are simple and often inexpensive to implement, but at the same time produce considerable changes in behavior. Nudges have been found to be successful in a variety of settings, improving healthy and pro-social behaviors (e.g., Giné et al., 2010; Breman, 2011; Schultz et al., 2008), adoption of better technologies (Duflo et al., 2011), saving rates (e.g., Madrian and Shea, 2001; Thaler and Benartzi, 2004; Chetty et al., 2009; Chetty et al., 2012) and energy efficiency and use (e.g., Allcott and Rogers, 2014; Ayres et al., 2013; Jessoe and Rapson, 2014; Reiss and White, 2008; Brown et al., 2013).

Among these interventions, labeling manipulations have attracted the attention of social scientists and economists in recent years (see, e.g., Newell and Siikamäki, 2014; Swartz et al., 2011; Mathios, 2000; Fischer, 2008; Kallbekken et al., 2013). Labels are often attached to cash transfers that, although unconditional to any specific use, are given a suggestive name with the intention to nudge recipients into socially desirable behaviors or to provide further information to consumers. Example of these types are the child tax credit in the US or child benefits in the UK. The 
literature typically studies the effectiveness of the label in promoting such desired behaviors and stress that standard economics would predict unconditional labeled cash transfers to be equivalent to an unconditional unlabeled cash transfers. ${ }^{1}$ However, recent evidence suggests that labeled transfers seem to be spent more than proportionally on the items suggested by the label (e.g., Beatty and Tuttle, 2015; Kooreman, 2000; Beatty et al., 2014; Blow et al., 2012).

This paper is different in that it asks whether labels may alter decisions on products related to the labeled good. The theory which underlies the disproportional impact of the label on the labeled good is mental accounting (Thaler, 1990).Mental accounting argues that households assign their income to categories of expenditure, thus when income is received that is labeled, it is disproportionately assigned into the labeled category. However it is unclear how individuals make "accounts" in their head and thus which goods the label impacts become an empirical question. Even in the case that it is clear that the account includes the goods in question, how related goods are impacted depend on the magnitude of counteracting income and substitution effects. The literature cited above classifies the labeling effect as encouraging behavior that policymakers would like to occur although labeling coudl be used for other purposes like agenda setting. Should the effect of the label "spillover" to decision on other goods, it becomes less clear that these altered behaviors are the decisions policymakers would like to encourage.

The UK Winter Fuel Payment (WFP) is an unconditional cash transfer into an

\footnotetext{
${ }^{1}$ Both of these types of transfers are uncommon with conditional cash transfers being most common, like Medicaid in the US and unemployment benefits in the UK.
} 
individuals current/checking account designed to combat the excess elderly winter mortality and morbidity associated with cold indoor climates. It provides households, which have a member 60 years of age (or older) in the qualifying week of a given year, with a lump sum annual payment. A person who turns 60 in a given year, but after the qualifying week, does not receives the payment. The WFP is not means tested nor is it mandated that the payment be spent on fuel. Though the WFP transfers cash that could be utilized for any expenditure, the label of the transfer induces households to use a larger portion of it to pay their energy bills than a nonlabeled transfer (Beatty et al., 2014). The rationale for this behavior is based on the framework of mental accounting. We interpret the theory that labeled income being assigned to a category as implying that households treat the WFP like a reduction in the price of energy. This affects directly the amount of money spent for fuel and can have indirect effects on substitute goods too. For instance, perceived lower price of energy might induce households to substitute away from more energy efficient technologies or renewables. While renewables are different than energy efficiency measures, and renewables are sometimes installed for different reasons (Andor et al., 2017), they have the potential to achieve the same goal set by the WFP, i.e., keeping elderly warm in winter, while also reducing the negative externalities from emissions. Our analysis shows that the WFP label has the unintended consequence of reducing the propensity to install renewable technologies. ${ }^{2}$

The identification strategy is based on the sharp eligibility criteria of the WFP

\footnotetext{
${ }^{2}$ Another notable example of counterproductive labels is Cialdini (2003).
} 
which allows for an estimation of the casual impact of the WFP on the propensity to install renewable energy with a regression discontinuity design (RDD). ${ }^{3}$ This analysis uses repeated cross-sections to compare thousand of households who are born just before or after a qualifying week in each year from 2008 to 2011. The identifying assumption here is that these households born few months apart are similar in their observed and unobserved characteristics and would have behaved similarly with respect to investing in renewable technology in the absence of the WFP. In other words, this assumption ensures that non-recipients represent a valid counterfactual to recipients near the discontinuity point (i.e., local randomization assumption).

Valid RDD estimation requires that other potential explanatory variables that affect the outcome are continuous around the treatment discontinuity point (see, e.g., Hahn et al., 2001 and Lee and Lemieux, 2010). We note that since WFP eligibility occurs around the same age as pension eligibility for females, there is the potential for a discontinuity in retirement for females to confound the effect of the WFP on propensity to install renewables. ${ }^{4}$ Additionally, the decision-making process concerning renewable technologies may not rest with the older members of the household if they rent their home (instead of owing) and/or contain more than two adults (e.g., older person living with their own children). To ensure that the results obtained from the RDD estimation identify the effect of the WFP, and not one of the issues discussed above, we restrict the sample to homeowners, living in a household composed

\footnotetext{
${ }^{3}$ For recent reviews of the RDD in economics and social sciences see Imbens and Wooldridge (2008); DiNardo and Lee (2011); Van der Klaauw (2008).

${ }^{4}$ Indeed, tests of discontinuity in employment for females show a large and statistically significant decrease in employment at 60 years of age in the qualifying week.
} 
by maximum two members in which the oldest is a male (whose pension eligibility age is 65). ${ }^{5}$ Outside of these identification concerns, RDD estimates are sensitive to the choice of bandwidth size (the window on either side of the cut off) and functional form. For this reason, we present estimates from various combinations of different bandwidths (6, 8 and 10) and functional forms (linear, quadratic and cubic) in a parametric estimation and different bandwidths $(6,3,2)$ in a non-parametric estimation.

Results consistently find a negative effect of the WFP on the probability to install renewables. Parametric models with optimal functional forms, as established by Akaike Information Criterion (AIC), show that the probability of installing renewables decreases by 1.2 percentage points for WFP recipients (from a baseline of $1.6 \%$. This drop corresponds to about $69 \%$ of households substituting away from renewable investments after receiving the payment (i.e., more than half of households who would have installed renewables are "discouraged" to do so just after receiving the payment). ${ }^{6}$ Given the universality of the WFP this is a considerable distortion, however the impact seems to dissipate as the oldest person gains in age. Non-parametric models and parametric models with those of age 60 removed, known as the "doughnut hole" model, find a negative and statistically significant drop in renewable installation also. Additionally, placebo WFP eligibility ages other than 60 do not find statistically significant changes in the propensity to install renewables.

Other falsification tests show that the WFP has no effect on the probability to in-

\footnotetext{
${ }^{5}$ Though this makes our result more like an average treatment effect on the treated given that the subsample is the one most likely to be impacted by the treatment.

${ }^{6}$ This is computed by taking the difference between portion of households predicted to have installed renewables with and without receiving the WFP at the cut off.
} 
vest in one's home through other large items, such as remodeling their kitchen, and that extra income that is not labeled does not effect the probability of installing renewables. Finally, we show that adding loft insulation (the most common energy efficiency improvement) is not affected by the WFP and it is argued that this is due to the plethora of programs by local governments and utilities to encourage loft insulation installation.

This analysis is the first to estimate the indirect effects of a labeled cash transfer payment by looking at the potential distortionary effects on related goods. These indirect effects are especially important in energy issues, in which negative externalities are pervasive and policies that seems at first effective, may ultimately lead to socially inefficient outcomes. We find that households are nudged away from sources which generate relatively cleaner energy. In other words, a distortionary effect on the renewable market is not a necessary evil to achieve the public health objective of reducing cold-related mortality and morbidity. The label can be changed such that it promotes harmony between health and energy policy. The impact of the WFP label on renewable energy investment is particularly concerning given current UK energy policy. The UK Committee on Climate Change (CCC) has outlined ambitious goals for improved household energy efficiency and uptake of renewable energy technologies. The scenario envisioned by the $\mathrm{CCC}$ for the UK to meet their carbon budgets requires substantial savings from the building sector. As a result of these climate change-driven energy goals, increased concern over the security of energy supplies and competitiveness of the UK economy, a number of high profile energy saving 
policies have been implemented in the last 5 years. Many target the residential sector, such as the Green Deal and Feed-in Tariff Scheme. These policies are designed to make it easier for citizens to recognize the future benefits of energy efficient choices and reduce the upfront cost of installing energy efficient and/or renewable technologies (Jaraite et al., 2017). The research here reveals that the WFP label does not fully support the UK goal of carbon emissions reductions, with the caveat that reducing excess winter mortality is also a goal. When it comes to unconditional transfers, labels should take into account indirect effects to avoid potential unintended consequences and lead behaviors towards more socially efficient outcomes.

The remainder of the paper is structured as follows. The next section provides a conceptual framework on the relationship between the WFP and household's installation of renewable energy. Section three describes the data, while Section four details the empirical strategy. Sections five discusses the results, associated robustness checks and provides some support of the labeling channel. Section six concludes the study.

\section{Background}

The WFP was initiated in 1997 by the UK government as a means to reduce excess winter morbidity and mortality in the elderly. At the time, the UK had one of the highest rates of winter mortality in Europe. Initially the payment was $£ 20$ per household, but in 2001 it increased to $£ 200$, and, for 60 to 79 years old, it has stayed 
at that level since then, although for in the period 2008-2010 it included extra onetime payments of $£ 50^{7}$ Households who have a member who is 60 or older at the beginning of the qualifying week are eligible to receive the WFP. ${ }^{8}$ Households who have not previously registered with the Department of Work and Pensions (DWP), the agency that manages the WFP, have to fill out a form to receive the payment. Those that have previously registered will automatically receive the payment. Almost all the qualified households do indeed receive the payment. ${ }^{9}$ Once a household is in receipt of the WFP, it continues to be paid until the DWP is notified of a change in circumstance that makes the household no longer eligible for the payment. The placement of the qualifying week has changed over time, however during the years in our data the qualifying week came in September. The payment is generally direct deposited into the eligible person's checking account in November and a letter is sent to them beforehand which states that they will be receiving the WFP. ${ }^{10}$ Important for this analysis is that the WFP is not means tested and all households which contain a member 60 or above at the qualifying week receive the payment. ${ }^{11}$

A simple model where the household produces energy services (e.g., heating)

\footnotetext{
${ }^{7}$ For a detail year-by-year change of rates, criteria and constant update on the WFP, please consult the full report by Steven Kennedy at the House of Commons Library available online at researchbriefings.parliament.uk/ResearchBriefing/Summary/SN06019.

${ }^{8}$ Additionally, the UK Government provides the Cold Weather Payment of $£ 25$ to low income households if the temperature in their area of residence is subzero for seven consecutive days. Our analysis does not include this payment. Given the small amount, our use of survey year dummies, and different eligibility criteria this will not confound our analysis.

${ }^{9}$ Beatty et al. (2014) cites a 90\% take up rate. Using self-reported data from the English Housing Survey this becomes $98 \%$ for the period of interest.

${ }^{10}$ To the best of our knowledge, no further information or suggestions are given about how a household should spend the money.

${ }^{11}$ This aspect of the WFP has proved quite controversial as many fuel poverty and austerity groups argue that the WFP should be altered to help the fuel poor exclusively.
} 
through the use of energy (e.g., electricity) and capital (e.g., renewable technologies) is utilized to show how the WFP could affect household decisions around renewable energy technologies. It is assumed that the household maximizes the production of energy services subject to a budget constraint. ${ }^{12}$ The household's production of energy services is assumed to follow a Cobb-Douglas production function and can be modeled using isoquant and isocost curves, which show the household's ability to purchase energy or capital constrained by total expenditure. ${ }^{13}$ In this setting, higher levels of capital imply lower levels of energy used for a given level of energy services. Standard economic theory assumes that income and cash transfers are always fungible: any unit of money can be substituted for another and that the source does not matter for rational consumers. A direct consequence of this is that the labeling of an income sources alone (cash or cash-equivalents such as vouchers) should not yield any sizable and statistically significant effect on spending choices. In other words, standard economic theory would predict that the WFP is seen as income. When WFP is treated as income, the WFP leads to a rightward shift of the isocost curve as households can increase the use of both capital and energy to produce more energy services. This is shown in Figure 1.

However, recent literature shows that cash transfers with a label attached is treated like a price subsidy to the labeled good. Conceptually, this is a violation of the fungibility assumption and can be explained by the mental accounting framework

\footnotetext{
${ }^{12}$ The household has a budget for all other goods which are abstained from here. The budget constraint for energy services is a part of overall budget constraint for all goods the household consumes.

${ }^{13} \mathrm{An}$ isocost curve here can be considered as a budget line for energy services.
} 


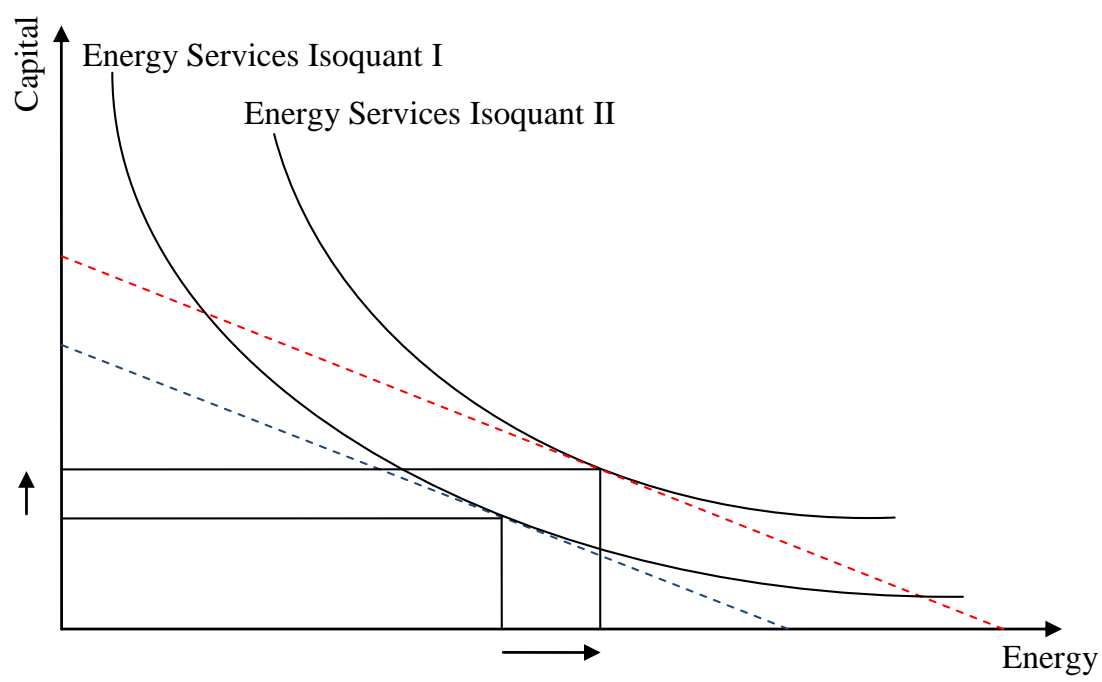

Figure 1: Impact of the WFP as income on use of energy and capital

proposed by Thaler in several works (e.g., Thaler, 1990, 2004). In this framework, individuals are thought to use simple heuristics to make financial and consumption decisions. In particular, individuals have mental budgets for different expenditure categories (food, clothes, and energy) that they treat separately. Which goods fall into which category (is coffee made at home treated differently than coffee purchased at a Starbucks, for example) is an open question. La Nauze (2017) finds that households in Australia disproportionately spend income generated through subsidies to produce solar power on electricity, another violation of the fungibility assumption. While La Nauze (2017)'s analysis finds that household-generated electricity and grid-generated electricity are in the same category, it is uncertain as to whether renewable energy capital would be treated in the energy category. 
If we assume electricity and renewable energy investments are in the same account, a labeled cash transfer is used disproportionately more to purchase goods suggested by the label. Mental accounting would pivot out the isocost curve to allow more energy to be used as in Figure 2. This result is in line with the findings of Beatty et al. (2014). In this case, the sign of the effect of the WFP on capital (i.e. renewable technologies) depends on the relative strength of the substitution effect and the output effect. If the substitution effect (towards energy and away from capital) dominates the output effect, less capital is used and vice versa. ${ }^{14}$ To summarize, our simple model predicts that households will reduce their investment in renewable energy only if the WFP is seen as a price subsidy to energy (and the substitution effect is stronger than the output effect). This refutable implication is taken to the data to determine if it has empirical validity.

A number of examples across a number of fields of economics have found evidence of mental accounting. Abeler and Marklein (2017) show that individuals change consumption according to the suggestion of the label in a field experiment conducted in a restaurant. Food stamps, a cash-equivalent benefit that can be exchanged for food, have also being studied extensively. The results are mixed with observational studies showing that the fungibility assumption is usually violated, while experimental evidence would suggest that agents act rationally. Beatty and Tuttle (2015) shows that an exogenous large increase in food stamp benefits caused households to increase food-at-home expenditure as well as increase households'

\footnotetext{
${ }^{14}$ To reflect the ambiguity of the sign of an energy price subsidy on the level of capital, Figure 2 shows no change in the level of capital used.
} 


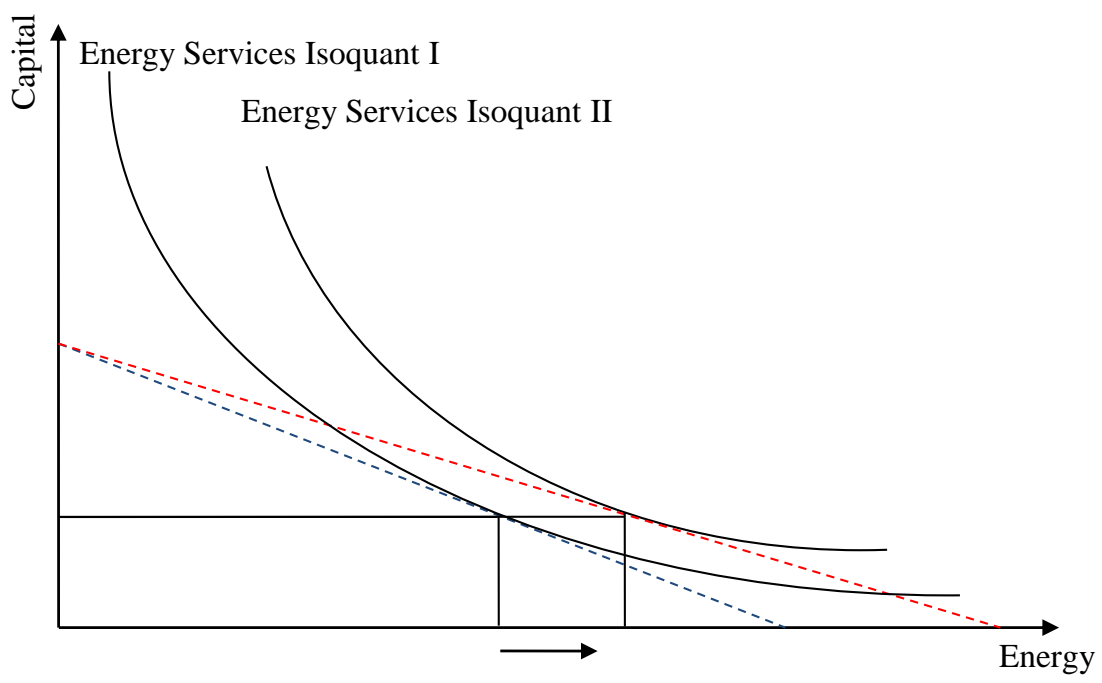

Figure 2: Impact of the WFP as a price subsidy to energy on use of energy and capital share of total expenditure allocated towards food-at-home expenditure. Recent work found that the cash incentives to education that are labeled, but not conditional on school attendance, performs as well as more expensive conditional cash transfers in Morocco (Benhassine et al., 2015). Hastings and Shapiro (2013) provide evidence that consumers have mental budgets for gasoline such that the income placed in this budget is not fungible. Beatty et al. (2014) estimate the effect of the WFP on share of total expenditure spent on fuel, holding total expenditure constant. They find that non-labeled transfers generally lead to a 3 percent increase in energy expenditures while the WFP has led to between a 13 and 60 percent increase. No other expenditure category was significantly affected by receiving the WFP.

The prediction of our model when households use mental accounting implies that 
the WFP label has indirect effects on the renewables market. Should the WFP lead to less renewable energy investment, it would imply that the label of the WFP leads households to see a lower price of energy and thus substitute away from renewable energy and towards more energy that makes pollution. In this scenario, the WFP label would lead (indirectly) to a socially inefficient outcome, namely an equilibrium in which a given indoor temperature is obtained with too much pollution. This outcome is also of concern because indoor temperatures can be kept at comfortable levels by employing different strategies (or combination of those), some of which are more socially optimal than just switching the heater on. Some of these alternative strategies include improving energy efficiency and/or installing renewable technologies at home.

\section{Empirical Approach}

The eligibility criterion based on age allows for an estimation of the effect of the WFP on renewable energy installations using a sharp RDD. In other words, assignment to the treatment is determined exogenously by the age of the oldest member in the qualifying week in September. Thus, households will be either treated by the WFP if eligible or not treated if not eligible. The empirical specification will then compare households who are immediately above and below the eligibility age with the identifying assumption that these households with similar observed and unobserved characteristics would have behaved similarly with respect to renewable energy 
installation in the absence of the WFP. In other words, this assumption ensures that households on the left-hand side of the cutoff represent a valid counterfactual and that the WFP is as "good as randomly assigned" near the discontinuity point (i.e., local randomization assumption). Now, let $\rho$ denote the causal effect of WFP on the probability of renewable energy installment; for small $\epsilon>0$ a formal representation of the causal effect can be given by the following equation:

$$
\rho=\lim _{\epsilon \rightarrow 0} \mathrm{E}\left(y \mid x=x_{0}+\epsilon\right)-\mathrm{E}\left(y \mid x=x_{0}-\epsilon\right),
$$

where $y$ is a dummy variable indicating whether the household has installed renewable technologies at home, $x$ is the age of the oldest member - the assignment variable and $x_{0}$ is the cut off age of 60 in the qualifying week. Note that this implies that there are 60 years old who are recipients (born on or before the qualifying week) and 60 years old who are not recipients (born after the qualifying week).

Equation 1 states that any jump in the propensity of renewable energy installment at the threshold can be interpreted as having been caused by the discontinuity in the WFP, under some specific conditions. The most important condition in our case is that nothing, other than eligibility to WFP, changes discontinuously around the threshold age. For households where females are the oldest member, there is likely to be a discontinuous change in employment status as the pension eligibility age for females is 60 years of age. Thus, we exclude these households from our sample. Additional identification concerns are that households which do not own 
their own home are unlikely to be the ones making decisions regarding renewable energy investments, as they require some alteration to the home's structure, and that households with three or more adults may have a decision-making process that is less likely to be impacted by the receipt of the WFP (a parent living with their children's family). To ensure that these issues do not confound the estimation, our sample does not include households which rent their home and those with three or more adult members. Further, in order to check for the validity of our design, we will be testing for the presence of discontinuities in observed covariates, in this case income, employment status, and educational attainment. The absence of any significant discontinuity will be taken as further reassurance that local randomization is an appropriate assumption.

Finally, the last condition pertains to the econometric specification and bandwidth size. Formally, we can write our econometric model as follows:

$$
y=\alpha+\beta_{1} \widetilde{x}+\cdots+\beta_{k} \widetilde{x}^{k}+\delta_{1} D \widetilde{x}+\cdots+\delta_{k} D \widetilde{x}^{k}+\rho D+\theta T+\lambda Z+\eta
$$

where $D$ is the treatment indicator that takes the value of 1 if the household receives the WFP and 0 otherwise, and $\widetilde{x}=x-x_{0}$ is the normalized age (i.e., centered around the cutoff) of the older member of the household. To allow for different functional forms on either side of the cutoff, our model includes interaction terms between the treatment indicator $D$ and $\widetilde{x}$ and its $k$ polynomial orders. ${ }^{15} T$ is a vector of time

\footnotetext{
${ }^{15}$ The normalized age, $\widetilde{x}=x-x_{0}$, gives a guarantee that the coefficient on $D$ is still a causal effect even after these interactions (Angrist and Pischke, 2009).
} 
dummies that control the survey fixed effects, and $Z$ is a vector of controls which include (log of) household income, employment status and educational attainment dummies. If the local randomization generated by the cut off date holds, the inclusion of controls improves precision only.

The order of the polynomial of $\widetilde{x}$ represents the shape of the preferences for installing renewable energy as age changes. While the assumption is that the preferences are smooth, this does not provide guidance as to the correct order of polynomial. The optimal polynomial order for the functional form is chosen using the AIC across different bandwidths.

Equation 2 can be estimated using different windows around the cut off age, i.e., bandwidth sizes. Note that as the bandwidth becomes larger, more data is considered, however households at either end of the spectrum are less likely to have similar observed and unobserved characteristics. Therefore, much wider bandwidths may give biased results of a causal effect. Narrower bandwidths, on the other hand, may reduce the precision of the regression model. For this reason, we employ the cross validation method of optimal bandwidth selection, suggested by Imbens and Lemieux (2008), which balances between bias and precision. To ensure that the parametric form is not biasing our results, we also estimate non-parametric locally weighted linear regressions using a triangular and rectangular kernel with narrower bandwidths selected using the method suggested by Imbens and Kalyanaraman (2012). ${ }^{16}$

Having established ways of selecting bandwidths and specifications is helpful,

\footnotetext{
${ }^{16}$ Triangular kernel assigns more weight to observations around the threshold age. The sensitivity of these local linear regressions was also assessed by re-estimating at double and half the optimal bandwidths.
} 
but following the best practices, we do not rely on one particular specification or bandwidth, because a range of estimations that are stable across different alternatives are more reliable than single sets of estimations. Each table reports the estimated coefficient of interest under three bandwidths and parametric models use three polynomials (linear, quadratic and cubic). ${ }^{17}$

\section{Data}

This analysis utilizes repeated cross-sections of a representative sample of UK households covering the period 2008-2011. The first dataset is the British Household Panel Survey (BHPS) Wave 18. The BHPS is a longitudinal survey covering on average 12,000 individuals and more than 5,000 households from 1991 to 2009, providing both individual and household-level information on a large variety of variables. Wave 18 is the only wave of the BHPS to ask households about the presence of renewable technologies at the home in 2008 and 2009. The second dataset is Understanding Society Survey (USS), which replaced the BHPS, but the first wave did not sample the same BHPS households. The USS samples more households than the BHPS did and asks some additional questions, but they are otherwise similar and can be pooled without any concern. This wave was collected in 2010 and 2011. While these surveys are both constructed as panels, these two waves do not overlap, so that the data used in the paper is effectively a repeated cross-section.

\footnotetext{
${ }^{17}$ Higher order polynomials might mislead the interpretation of results and are not used in the paper, see Gelman and Imbens (2014).
} 
Both waves of the BHPS and USS ask each household "Have you installed ..." solar photovoltaic (PV) panels, solar water heaters or a micro wind turbine. Ideally, we would have liked to have the exact date of installation of these renewables. However, other waves of the BHPS and USS do not contain these questions. Our work therefore assumes that this measure is a good proxy for installation at the time of the survey. Although not ideal, we believe that this assumption is unlikely to introduce a bias in the analysis and that, importantly, it is supported by the data. For instance, the most popular installed renewable in our sample was solar PV and by far the biggest increase in generation of solar PV came from the years in our sample. According to data from the Department of Energy and Climate Change, the amount of solar PV generation in the year before our data (2007) was 1.2 thousand tons of oil equivalent (toe) while generation in the last year of our sample (2011) was 21 thousand toe.

If anything, using this variable goes against finding a discontinuity at the cut off. Any jump around the eligibility age would need to be explained by a past behavior of those (and only those) who are turning 60 in September in each year we analyze (2008 to 2011). To be detected by our data, this sharp propensity to install renewables should have been occurred at the end of the 90 s by our cohort of 60 years old. This does not look very plausible. To the best of our knowledge, no such a behavior is detectable in the past and the data show that the amount of renewables installed by households in the UK was negligible at the end of the 90s.

Our outcome variable $y$ equals one if any of the three renewable technologies 
have been installed and is zero otherwise. ${ }^{18}$ Solar PV systems are mounted on roofs to produce electricity that is either used by the household or exported to the transmission grid. The generation that is used by the household reduces its expenditure on energy. According to the Energy Savings Trust, a typical solar PV system will generate up to 75 percent of a household's electricity needs. Similar arguments hold for micro-wind turbines, which can generate up to three times the average household's electricity consumption, and solar water heaters, which save around $£ 70$ a year. ${ }^{19}$

Given the eligibility requirement of the WFP discussed above, a sharp RDD requires the assignment variable $x$ be observable. Here, $x$ is the age of the oldest member of the household during the month of September in the year of the survey. In other words, not every household in which the oldest male member is 60 is treated. The data provides the month and year of birth as well as the month and year of the survey. This enables us to compute the age of the oldest member of the household with extreme precision, i.e., removing any potential measurement error in $x$, especially at 60.

Using this data, we construct $x$ in the following way,

\footnotetext{
${ }^{18} \operatorname{Pr}(y=1 \mid x)$ is therefore the propensity to invest in renewables.

${ }^{19}$ There are no subsidy schemes that the authors are aware of that restrict eligibility to 60 and over. The microrenewable Feed-In Tariffs introduced in 2010 are not based on age. We control for the impact of the Feed-In Tariffs with year fixed effects. There were two tariffs begun in 2010, a generation tariff and an export tariff. The generation tariff was a 20 year contract to pay a fixed amount per kWh (depending on size of the system). The export tariff was 3 pence per $\mathrm{kWh}$ (about $1 / 3$ of the retail price of electricity) and was fixed at $50 \%$ of generation.
} 


$$
x= \begin{cases}S Y-B Y & \text { if } 1 \leq B M<9 \text { and } 10 \leq S M \leq 12 \\ S Y-B Y-1 & \text { if } 1 \leq B M<9 \text { and } 1 \leq S M<9 \\ S Y-B Y-1 & \text { if } 10 \leq B M \leq 12 \text { and } 1 \leq S M \leq 12,\end{cases}
$$

where $S Y$ and $B Y$ denote survey year and birth year respectively, and $S M$ and $B M$ denote survey month and birth month respectively. Thus, in the first case, $x=$ $S Y-B Y$ if the oldest member of a household was born from January to August and surveyed from October to December. ${ }^{20}$ For other combinations of $B M$ and $S M$, we subtract 1 from $S Y-B Y$. In the first case, the oldest members aged 60 are considered as 60, i.e., treated, but in the second and third cases, they are considered as 59 because they are not eligible for the WFP. The assignment variable, $x$, is then used to create a discontinuity dummy, $D$, which is equal to one if the oldest member of a household is 60 or older (and thus eligible for the WFP) and is zero otherwise (e.g. $D=1\{x \geq 60\}){ }^{21}$

To improve sampling variability, some models include the following covariates: whether the respondent is employed, the log of annual gross household income, and a set of educational attainment dummies: whether the respondent has obtained higher

\footnotetext{
${ }^{20}$ The eligibility criterion for the WFP is that the oldest member of a household turns into 60 before a given date in September. As the data has no information about day or week of birth, we do not know the eligibility of households with the oldest members born in September. We drop those households.

${ }^{21}$ As the take up of the WFP is above $95 \%$ according to Beatty et al. (2014), we consider $D$ as a treatment dummy where 1 implies that a household receives the WFP and 0 otherwise. In this way, we consider the sharp RDD where the probability of receiving the WFP, $\operatorname{Pr}(D=1 \mid x)$, is sharply discontinuous at 60 . A special release of the 2010 version of the English Housing Survey did include whether the household was in receipt of the WFP. The correlation of receipt of the WFP and the specification of our discontinuity dummy $D$ (using age of the oldest member in the qualifying week) was above $98 \%$.
} 
education, an academic degree, high school advanced qualifications (called A-levels in UK), standard high school qualifications (called O-levels in UK) and no qualifications. Summary statistics of these variables are available in Table 1 for both recipients (treated) and non-recipients. ${ }^{22}$

Table 1: Summary Statistics (bandwidth=10)

\begin{tabular}{|c|c|c|c|c|c|c|}
\hline \multirow[b]{2}{*}{ Variable } & \multicolumn{2}{|c|}{ Recipients } & \multicolumn{2}{|c|}{ Non-Recipients } & \multicolumn{2}{|c|}{ Difference } \\
\hline & Mean & $\mathrm{N}$ & Mean & $\mathrm{N}$ & T-stat & P-value \\
\hline Renewable energy installment & 0.015 & 2363 & 0.009 & 1293 & -1.61 & 0.11 \\
\hline Employment (1=yes, $0=$ no $)$ & 0.334 & 2363 & 0.821 & 1293 & 31.85 & 0.00 \\
\hline Household size & 1.832 & 2363 & 1.735 & 1293 & -7.05 & 0.00 \\
\hline Log of annual household income & 8.088 & 2363 & 8.366 & 1293 & 5.93 & 0.00 \\
\hline Higher education $(1=\mathrm{yes}, 0=\mathrm{no})$ & 0.075 & 2363 & 0.106 & 1293 & 3.20 & 0.01 \\
\hline Degree $(1=$ yes, $0=$ no $)$ & 0.117 & 2363 & 0.148 & 1293 & 2.64 & 0.01 \\
\hline Advanced qualification $(1=$ yes, $0=$ no $)$ & 0.156 & 2363 & 0.196 & 1293 & 3.01 & 0.03 \\
\hline Qualification (1=yes, $0=$ no) & 0.234 & 2363 & 0.277 & 1293 & 2.81 & 0.01 \\
\hline No qualifications $(1=$ yes, $0=$ no $)$ & 0.416 & 2363 & 0.274 & 1293 & -8.64 & 0.00 \\
\hline
\end{tabular}

Note: This table reports summary statistics of the variables used to estimate the effect of the WFP on the propensity of renewable energy installment and compare WFP recipients and non-recipients. All the variables are from wave 18 of the British Household Panel Survey (BHPS) which covers the year 2008 and 2009, and wave 1 of Understanding Society Survey (USS) for 2010 and 2011. The sample includes home owners whose household size is two or lower and the oldest member is male with age between 50 and 70 (i.e., bandwidth size of 10).

\section{Results}

\subsection{Main Results}

Figure 3 provides a graphical representation of the estimated effects using a band-

width of 10. Each dot represents the propensity of installing renewable energy tech-

\footnotetext{
${ }^{22}$ To test the validity of our identification strategy, we will check for discontinuity of these covariates in the next section, among other things.
} 


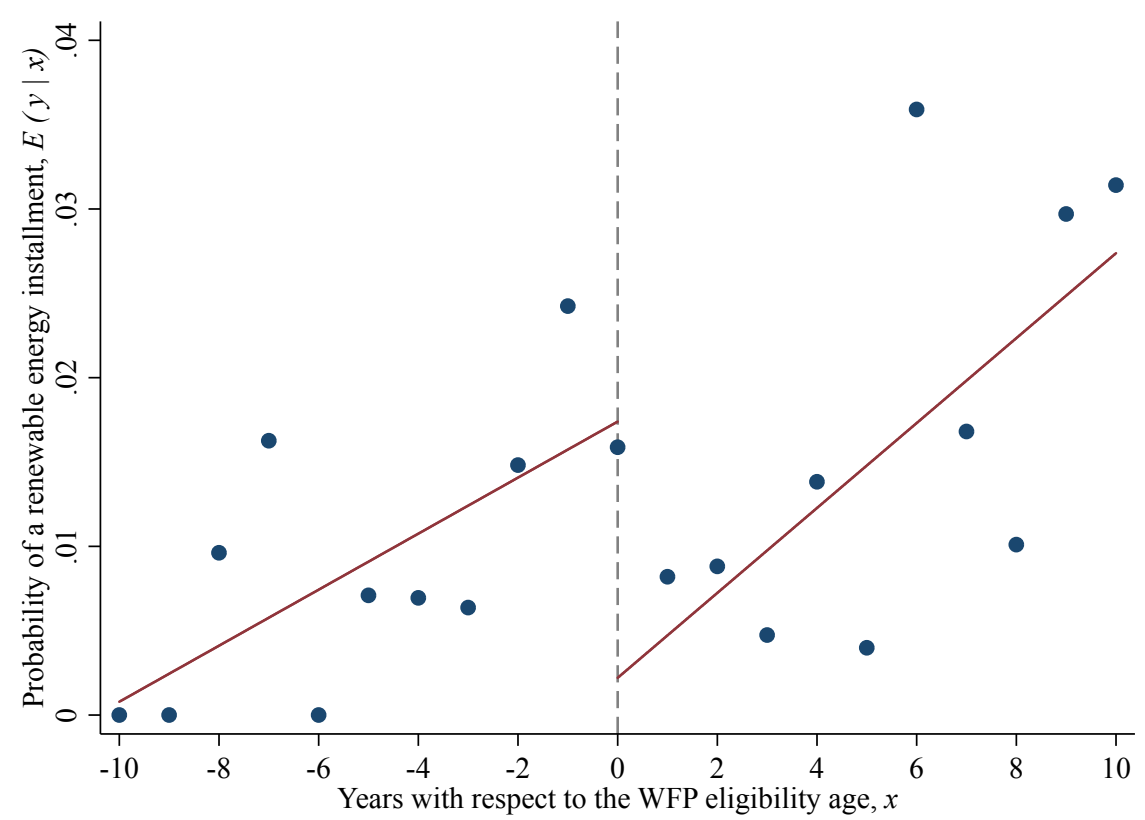

Figure 3: Graphical representation of discontinuity in the installation of renewables around the WFP eligibility age

nology, mean of $y$ for a particular age-year (i.e., they are not single observations), with linear best fit lines through the points on either side of the cut-off. ${ }^{23}$ This provides first evidence that households who are in receipt of the WFP are less likely to install renewable technologies at home. This is in accordance with the prediction of our model under the mental accounting framework. The WFP is seen as energy price subsidy, not as cash income (and substitution effect dominates output effect, see Figure 2). However, the impact seems to be short-run as the propensity to install renewables dips after 60 but increases from around age 65 .

Table 2 shows the estimated values of $\rho$ from equation (2) under three different bandwidths $(6,8$ and 10$)$, three orders of polynomials (linear, quadratic and cubic)

\footnotetext{
${ }^{23}$ The horizontal axis denote the number of years with respect to the WFP receipt. This graph was obtained using the -biscatter- command written by Michael Stepner for Stata.
} 
and with and without control variables. ${ }^{24}$ All models interact the polynomial of age with the treatment variable to allow for different functional forms on either side of the discontinuity. According to the Imbens and Lemieux (2008) cross validation method, the optimal bandwidth is 10 (for details, see Figure A.1 in Appendix).

Standard errors are clustered at age level and corrected for the bias arising from small clusters as shown by Brewer et al. (2013). ${ }^{25}$ However, for robustness purposes, Table A.2 in Appendix reports $p$-values using the wild cluster bootstrapped tprocedure, with imposition of the null hypothesis for each coefficient, which Cameron et al. (2008) shown to greatly improve inference with very few clusters. ${ }^{26}$ The significance levels reported using these two approaches are identical. Thus we report only the bias-corrected clustered standard errors because they are less computationally demanding.

The discontinuity parameters are all negative with estimates that range from 1 to 3.5 percentage points, indicating that the WFP reduces the likelihood of investing in renewables at home. The inclusion of controls do not change the results - providing a first indication that the local randomization assumption holds. The estimates in Table 2 use a linear probability model. Table A.3 runs the same model with a logit

\footnotetext{
${ }^{24}$ The optimal polynomial order identified using the AIC is denoted by the subscript letter $a$. Table A.1 in Appendix reports the values of AIC for each specification.

${ }^{25}$ These bias-corrected standard errors are computed using the cluster option in Stata. This computes a t-statistic with clustered robust standard errors that uses residuals scaled by $\sqrt{\frac{G(N-1)}{(G-1)(N-K)}} \approx \sqrt{\frac{G}{(G-1)}}$, and critical values from at distribution with $(G-1)$ degrees of freedom, where $G$ is the number of clusters, $N$ is the total number of observations, $K$ is the number of coefficients to be estimated. See Brewer et al. (2013) for more details.

${ }^{26} p$-values from bootstrapped t-statistics were obtained by using the Stata command bootwildet by Mansi and Scott (2015) and available at http://www.ifs.org.uk/publications/6231. The program was downloaded in June 2015.
} 
Table 2: The effect of the WFP on renewable energy installment

\begin{tabular}{|c|c|c|c|c|c|c|}
\hline \multirow{2}{*}{ Bandwidth } & \multicolumn{3}{|c|}{ Without controls } & \multicolumn{3}{|c|}{ With controls } \\
\hline & Linear & Quadratic & Cubic & Linear & Quadratic & Cubic \\
\hline \multirow[t]{3}{*}{10} & $-0.012 * * a$ & $-0.013^{*}$ & $-0.028 * * *$ & $-0.012 * a$ & $-0.014^{*}$ & $-0.030 * * *$ \\
\hline & [0.006] & {$[0.007]$} & {$[0.004]$} & {$[0.006]$} & {$[0.007]$} & [0.004] \\
\hline & $\mathrm{N}=3656$ & $N=3656$ & $\mathrm{~N}=3656$ & $\mathrm{~N}=3656$ & $N=3656$ & $\mathrm{~N}=3656$ \\
\hline \multirow[t]{3}{*}{8} & $-0.009^{a}$ & $-0.023 * * *$ & $-0.023 * * *$ & -0.009 & $-0.024 * * *$ & $-0.025 * * * a$ \\
\hline & {$[0.006]$} & {$[0.005]$} & {$[0.006]$} & {$[0.007]$} & {$[0.006]$} & [0.006] \\
\hline & $\mathrm{N}=3074$ & $\mathrm{~N}=3074$ & $\mathrm{~N}=3074$ & $\mathrm{~N}=3074$ & $\mathrm{~N}=3074$ & $\mathrm{~N}=3074$ \\
\hline \multirow[t]{3}{*}{6} & $-0.018 * * a$ & $-0.015 * * *$ & $-0.035 * * *$ & $-0.018 * *$ & $-0.016 * * *$ & $-0.036 * * * a$ \\
\hline & {$[0.006]$} & {$[0.004]$} & {$[0.005]$} & {$[0.007]$} & [0.004] & [0.005] \\
\hline & $\mathrm{N}=2411$ & $\mathrm{~N}=2411$ & $\mathrm{~N}=2411$ & $\mathrm{~N}=2411$ & $\mathrm{~N}=2411$ & $\mathrm{~N}=2411$ \\
\hline
\end{tabular}

Note: This table reports the estimated coefficients from sharp RDDs of the propensity to install renewable technology on an indicator variable for whether the household received the WFP using different polynomials (linear, quadratic and cubic) and bandwidths (6,8 and 10). Each regression includes year of survey fixed effects and a series of interactions between the treatment variable and normalized age. The last three columns include also log of household income, employment and education qualification dummies. See equation 2 for more detail. The estimation sample includes only home owners whose household size is two or lower and the oldest member is male. Standard errors in brackets are adjusted for clustering at age level. * $p<0.10$, ** $p<0.05, * * * p<0.01$. The subscript letter $a$ denotes optimal polynomial orders according to the AIC statistics (see Table A.1). The optimal bandwidth is equal to 10 according to the cross validation method suggested by Imbens and Lemieux (2008).

specification and finds similar sign and significance. With an eye on robustness we estimate the same model excluding year 2011, which have few observations. Table A.4 reports result that confirms the impact of WFP on renewable installations.

As specified above, the basic underlying assumption of the RDD is local random assignment around the cutoff age of 60 in the qualifying week. One way to check the validity of the above results is to examine whether the covariates are discontinuous around that threshold. To test the local randomization, we check discontinuities in the covariates (Imbens and Lemieux, 2008). One may argue that around the WFP eligibility age other things change that could be related to the outcome of interest, for 
Table 3: Discontinuities in observed covariates (bandwidth=10)

\begin{tabular}{lcc}
\hline & Discontinuity & Standard error \\
\hline Employment $(1=$ yes, $0=$ no $)$ & -0.008 & {$[0.24]$} \\
Heating fuel type $(1=$ gas, $0=$ others $)$ & 0.018 & {$[0.02]$} \\
Car Available $(1=$ yes, $0=$ no $)$ & 0.014 & {$[0.02]$} \\
Log of annual household income & -0.042 & {$[0.05]$} \\
Higher education $(1=$ yes, $0=$ no $)$ & -0.013 & {$[0.11]$} \\
Degree $(1=y e s, 0=$ no $)$ & 0.008 & {$[0.01]$} \\
Advanced qualifications $(1=$ yes, $0=$ no $)$ & -0.005 & {$[0.01]$} \\
Qualifications $(1=$ yes, $0=$ no $)$ & 0.033 & {$[0.02]$} \\
No qualifications $(1=$ yes, $0=$ no $)$ & -0.023 & {$[0.02]$} \\
\hline
\end{tabular}

Note: This table reports the estimated coefficients from seemingly unrelated regressions (SUR) of sharp RDDs of each reported variable on an indicator for whether the household received the WFP using a bandwidth of 10 and optimal polynomials. Each regression includes the optimal polynomial order of normalized age $(\widetilde{x})$. This varies with each regression. Every model includes year of survey fixed effects and a series of interactions between the treatment variable and normalized age $(\widetilde{x})$. The estimation sample includes only home owners whose household size is two or lower and the oldest member is male. Standard errors in brackets are adjusted for clustering at age level. $* p<0.10, * * p<0.05, * * * p<0.01$.

example employment status. ${ }^{27}$ Indeed, changes in pension or other benefit eligibility may alter labor supply decisions. ${ }^{28}$ In what follows, we check for discontinuity in the following set of variables: employment status, household size, (log of) annual household income and a set of education indicators. Every one of these variable is regressed on the treatment indicator, $D$, normalized age $(\widetilde{x})$, their interactions $(D \widetilde{x})$ and interactions with polynomials under the optimal bandwidth of 10. Optimal polynomial order varies across different equations. Each regression includes survey year

\footnotetext{
${ }^{27}$ Another issue might be whether people have a higher propensity to change homes around the same age. The dataset provide information concerning the age at which the household moved into their current home. People are most likely to move into their home at the age of 35 and the propensity falls smoothly as age increases. A visual inspection of this data reveals no jump in propensity to move around the discontinuity. Results are not shown but are available upon request.

${ }^{28}$ In addition to the checks for discontinuity in employment, Blundell et al. (2011) find no evidence of a discontinuity in male labor supply at the intensive or extensive margin at the cutoff age of 60 .
} 
dummies. As the number of covariates increases, some discontinuities might be statistically significant by random chance. As suggested by Lee and Lemieux (2010), regression of each covariate is run as seemingly unrelated regression (SUR) to perform the test of joint discontinuities. Table 3 shows the coefficient of the discontinuity for every covariate. All covariates are not statistically significantly discontinuous at the cutoff

\subsection{Robustness}

One may be concerned that households anticipate the receipt of the WFP and alter their behavior before turning 60 . This may cause a "bunching" around the discontinuity which manifests itself as a lack of installation of renewable technologies. This could potentially bias our estimates. Given that a RDD compares the mean renewable technology installation outcome as one approaches the discontinuity from either side, dropping the discontinuous point should not significantly alter the estimate of the effect of the discontinuity (Barreca et al., 2011). This is known as the "doughnut hole" estimation and the results are given in Table 4. All estimates are negative and most are statistically significant. These estimates lead us to conclude that anticipation of the WFP is not a concern.

The estimated causal effects shown so far are all from parametric RDDs: linear, quadratic or cubic. Technically, the linear specification in Table 2 is a (nonparametric) local linear regression with rectangular kernel, i.e., a function which gives uniform weight to all observations. Alternatively, one could use triangular ker- 
Table 4: The effect of the WFP on renewable energy installment excluding age 60

\begin{tabular}{|c|c|c|c|c|c|c|}
\hline \multirow{2}{*}{ Bandwidth } & \multicolumn{3}{|c|}{ Without controls } & \multicolumn{3}{|c|}{ With controls } \\
\hline & Linear & Quadratic & Cubic & Linear & Quadratic & Cubic \\
\hline 10 & $\begin{array}{c}-0.016 * * * \\
{[0.005]} \\
\mathrm{N}=3467\end{array}$ & $\begin{array}{c}-0.018 * * \\
{[0.008]} \\
\mathrm{N}=3467\end{array}$ & $\begin{array}{c}-0.035 * * * \\
{[0.008]} \\
N=3467\end{array}$ & $\begin{array}{c}-0.016 * * \\
{[0.006]} \\
\mathrm{N}=3467\end{array}$ & $\begin{array}{c}-0.019 * * \\
{[0.009]} \\
\mathrm{N}=3467\end{array}$ & $\begin{array}{c}-0.037 * * * \\
{[0.008]} \\
\mathrm{N}=3467\end{array}$ \\
\hline 8 & $\begin{array}{c}-0.012 * \\
{[0.006]} \\
\mathrm{N}=2885\end{array}$ & $\begin{array}{c}-0.031 * * * \\
{[0.009]} \\
\mathrm{N}=2885\end{array}$ & $\begin{array}{c}-0.015 \\
{[0.011]} \\
\mathrm{N}=2885\end{array}$ & $\begin{array}{c}-0.012 * \\
{[0.007]} \\
\mathrm{N}=2885\end{array}$ & $\begin{array}{c}-0.032 * * * \\
{[0.009]} \\
\mathrm{N}=2885\end{array}$ & $\begin{array}{c}-0.017 \\
{[0.013]} \\
\mathrm{N}=2885\end{array}$ \\
\hline 6 & $\begin{array}{c}-0.024 * * * \\
{[0.007]} \\
\mathrm{N}=2222\end{array}$ & $\begin{array}{c}-0.011 \\
{[0.008]} \\
N=2222\end{array}$ & $\begin{array}{c}-0.058 * * * \\
{[0.013]} \\
\mathrm{N}=2222\end{array}$ & $\begin{array}{c}-0.025 * * * \\
{[0.008]} \\
\mathrm{N}=2222\end{array}$ & $\begin{array}{c}-0.012 \\
{[0.009]} \\
N=2222\end{array}$ & $\begin{array}{c}-0.061 * * * \\
{[0.012]} \\
\mathrm{N}=2222\end{array}$ \\
\hline
\end{tabular}

Note: This table reports the estimated coefficients from sharp RDDs of the propensity to install renewable technology on an indicator variable for whether the household received the WFP using different polynomials (linear, quadratic and cubic) and bandwidths (6, 8 and 10). Each regression includes year of survey fixed effects and a series of interactions between the treatment variable and age. The last last three columns include also log of household income, employment and education qualification dummies. See equation 2 for more detail. The estimation sample includes only home owners which household's size is two or lower and the oldest member is male. Standard errors in brackets are adjusted for clustering at age level. $* p<0.10$, ** $p<0.05$, *** $p<0.01$.

nel, a weighting function which gives more "importance" to observations near the cut off. Further, Imbens and Kalyanaraman (2012) provide a formula for the optimal bandwidth that is suggested to be used in the case of local linear regressions. The method yields an optimal bandwidth of 1.6 (which for simplicity is rounded to 2) and Table 5 shows local linear regressions with and without covariates using rectangular and triangular kernel with different bandwidths (the optimal 2, 3 and 4) for robustness purposes. Every estimated coefficient is statistically significant at $1 \%$ level and adding covariates does not make any difference.

To further examine the affect of the WFP, equation 2 is estimated for households above and below median income. Table 6 show the estimates. The impact of the WFP 
Table 5: Local linear regressions with triangular and rectangular kernels

\begin{tabular}{lccccc}
\hline \multirow{2}{*}{ Bandwidth } & \multicolumn{2}{c}{ Without controls } & & \multicolumn{2}{c}{ With controls } \\
\cline { 2 - 3 } \cline { 5 - 6 } & Triangular & Rectangular & & Triangular & Rectangular \\
\hline 4 & $-0.019 * * *$ & $-0.018 * * *$ & & $-0.009 * * *$ & $-0.018 * * *$ \\
& {$[0.000]$} & {$[0.000]$} & & {$[0.000]$} & {$[0.000]$} \\
3 & $-0.018^{* * *}$ & $-0.019 * * *$ & & $-0.021 * * *$ & $-0.019 * * *$ \\
& {$[0.000]$} & {$[0.000]$} & & {$[0.000]$} & {$[0.000]$} \\
2 & $-0.008 * * *$ & $-0.014 * * *$ & & $-0.020 * * *$ & $-0.014 * * *$ \\
& {$[0.000]$} & {$[0.000]$} & & {$[0.000]$} & {$[0.000]$} \\
\hline
\end{tabular}

Note:This table reports the estimated coefficients from local linear RDDs of the propensity to install renewable technology on an indicator variable for whether the household received the WFP using triangular and rectangular kernels and different bandwidths ( 2,3 and 4; where 2 is the optimal bandwidth according to the method devised by Imbens and Kalyanaraman, 2012). The first two columns do not include any control variable, while the third and fourth one includes log of household income, employment and education qualification dummies. The estimation sample includes only home owners which household's size is two or lower and the oldest member is male. Standard errors in brackets are adjusted for clustering at age level. $* p<0.10, * * p<0.05, * * * p<0.01$.

is similar in magnitude across the two groups but consistently statistically significant for the above median households. This result is not driven by a lack of installation of renewables by below median households. A t-test on the mean difference in installation between above and below median income households was statistically insignificant $(\mathrm{T}=1.13)$. To our knowledge there is little evidence of differential effects of mental accounting across income groups. This would seem to be a promising avenue for future research. For now, our model seems to predict more precisely that richer households - who are less in need of support - are nudged away from cleaner energy sources, while the effect of WFP has greater variability on poorer households. This is however potentially good news from a policy perspective: the sacrifice of energy policy objective in the name of a public health one does not seem to be necessary. 
The implication is to devise a different label that will support the poorer households

without distorting the renewable market for richer households.

Table 6: The effect of the WFP on renewable energy installment by income groups

\begin{tabular}{|c|c|c|c|c|c|c|}
\hline \multirow{2}{*}{ Bandwidth } & \multicolumn{3}{|c|}{ Below Median } & \multicolumn{3}{|c|}{ Above Median } \\
\hline & Linear & Quadratic & Cubic & Linear & Quadratic & Cubic \\
\hline \multirow[t]{3}{*}{10} & -0.002 & -0.006 & $-0.038 * * *$ & $-0.022 * * *$ & $-0.021 * * *$ & $-0.027 * * *$ \\
\hline & {$[0.011]$} & {$[0.016]$} & [0.007] & [0.004] & {$[0.005]$} & {$[0.005]$} \\
\hline & $\mathrm{N}=1862$ & $\mathrm{~N}=2885$ & $\mathrm{~N}=2885$ & $\mathrm{~N}=1794$ & $\mathrm{~N}=1794$ & $\mathrm{~N}=1794$ \\
\hline \multirow[t]{3}{*}{8} & 0.003 & $-0.024 * *$ & $-0.027 * *$ & $-0.020 * * *$ & $-0.027 * * *$ & $-0.024 * * *$ \\
\hline & {$[0.014]$} & {$[0.011]$} & {$[0.010]$} & [0.004] & {$[0.006]$} & [0.008] \\
\hline & $\mathrm{N}=1532$ & $\mathrm{~N}=1532$ & $\mathrm{~N}=1532$ & $\mathrm{~N}=1542$ & $\mathrm{~N}=1542$ & $\mathrm{~N}=1542$ \\
\hline \multirow[t]{3}{*}{6} & -0.011 & $-0.017 *$ & $-0.053 * * *$ & $-0.028 * * *$ & $-0.019 * * *$ & -0.020 \\
\hline & {$[0.013]$} & {$[0.009]$} & [0.013] & {$[0.005]$} & {$[0.003]$} & {$[0.012]$} \\
\hline & $\mathrm{N}=1175$ & $\mathrm{~N}=1175$ & $\mathrm{~N}=1175$ & $\mathrm{~N}=1236$ & $\mathrm{~N}=1236$ & $\mathrm{~N}=1236$ \\
\hline
\end{tabular}

Note: This table reports the estimated coefficients from sharp RDDs of the propensity to install renewable technology on an indicator variable for whether the household received the WFP using different polynomials (linear, quadratic and cubic) and bandwidths (6, 8 and 10). Each regression includes year of survey fixed effects and a series of interactions between the treatment variable and age, log of household income, employment and education qualification dummies. The estimation sample includes only home owners which household's size is two or lower and the oldest member is male. The first three columns are for household with below median income while the second three columns are for households above median income. See equation 2 for more detail. Standard errors in brackets are adjusted for clustering at age level. $* p<0.10,{ }^{*} * p<0.05, * * * p<0.01$.

\subsection{Mechanism and Falsification Tests}

To this point, the paper has shown that the WFP generates a significant distortion in the renewable markets. In this section we provide some evidence that the label is the mechanism which drives this result, i.e., the label nudges households to think of the payment as an energy subsidy which move people away from capital towards energy use. 
A first way to test of the labeling mechanism is to determine whether non-labeled changes in income affect the probability of installing renewables. Ideally this nonlabeled income would be about the same magnitude as the WFP. The waves of the BHPS and USS that we used to estimate the impact of the WFP on the probability of installing renewables, include questions related to extra income, generally described as income not part of a households usual pay (which both surveys ask about). The BHPS is more specific about breaking apart these extra income into categories like lottery winnings or bequests but the USS does not break them apart. The amount of this extra income is summed across each household and an estimation is run separately to determine whether the presence of extra income or the amount of extra income affects the probability of installing renewables ${ }^{29}$ The median amount of extra income in the sample is $£ 184$. The results are given in Table 7. All estimates are indistinguishable from zero.

If the mechanism which drives our results of a reduced propensity to install renewable energy technologies is the WFP, and in particular its suggestive label, than the propensity to make other investments in durable goods on one's home should not vary by whether the household receives the WFP. This proposition is tested by examining whether receipt of the WFP leads to a change in the propensity to invest in non-energy related goods, which costs are similar to the renewable energy investments considered above. Data from the English Housing Survey for the years 2006-2010 is used to create falsification outcomes which takes the value of one if

\footnotetext{
${ }^{29}$ Unfortunately, this test can not tell us how an unlabeled subsidy to renewables would behave and we do not have a way to test the impact of an unlabeled subsidy.
} 
Table 7: Effect of Non-labeled income changes on renewable energy installment

\begin{tabular}{lccccc}
\hline \multirow{2}{*}{ Variable } & \multicolumn{2}{c}{ Whole Sample } & & \multicolumn{2}{c}{ Homeowners Aged 50-70 } \\
\cline { 2 - 3 } \cline { 6 - 7 } Presence of Extra Income & 0.001 & 0.001 & & $-2.16 \mathrm{e}-04$ & $-1.08 \mathrm{e}-4$ \\
& {$[0.001]$} & {$[0.01]$} & & {$[0.001]$} & {$[0.002]$} \\
& $\mathrm{N}=37,213$ & $\mathrm{~N}=37,213$ & & $\mathrm{~N}=13,455$ & $\mathrm{~N}=13,455$ \\
\hline \multirow{2}{*}{ Amount of Extra Income } & $1.82 \mathrm{e}-09$ & $-2.98 \mathrm{e}-09$ & & $-1.04 \mathrm{e}-08$ & $-3.92 \mathrm{e}-08$ \\
& {$[2.47 \mathrm{e}-08]$} & {$[2.60 \mathrm{e}-08]$} & & {$[2.43 \mathrm{e}-08]$} & {$[6.13 \mathrm{e}-08]$} \\
& $\mathrm{N}=37,213$ & $\mathrm{~N}=37,213$ & & $\mathrm{~N}=13,455$ & $\mathrm{~N}=13,455$ \\
\hline
\end{tabular}

Note: This table reports the coefficients from an OLS and the marginal effects from a logit model of the propensity to install renewable technology using two samples. Each regression includes year of survey fixed effects, age of oldest member, log of household income, and tenure. Standard errors in brackets are adjusted for clustering at age level. * $p<0.10, * * p<0.05, * * * p<0.01$.

the household has remodeled their kitchen (replaced units, worktops, and sinks), installed a burglar alarm, or replaced the gutters in the last 12 months and zero otherwise. If the WFP leads households to alter their decisions around energy investments only, the coefficient on receipt of WFP should not statistically alter the propensity to undertake one of the outcomes listed above. Table 8 shows the estimation results for equation (2) with first three columns showing the kitchen remodeling estimation, the second three columns showing the installation of a burglar alarm estimation, and the third three columns showing gutter replacement estimation. ${ }^{30}$ The estimated effect of the WFP in Table 8 is rarely statistically significant and moves from positive to negative across the different bandwidths and polynomial orders.

\footnotetext{
${ }^{30}$ The English Housing Survey (EHS) does not provide the month of birth so the assignment variable is based on age of the oldest household member at the date of interview. As a result, households whose oldest member is 59 and interviewed before September and households whose oldest member is 60 and interviewed after September are removed from the analysis.
} 
Table 8: Falsification Tests of the Effect of WFP on non-energy goods

\begin{tabular}{|c|c|c|c|c|c|c|c|c|c|}
\hline \multirow{2}{*}{ Bandwidth } & \multicolumn{3}{|c|}{ Kitchen Remodelling } & \multicolumn{3}{|c|}{ Installing a Burglar Alarm } & \multicolumn{3}{|c|}{ Replacing Gutters } \\
\hline & Linear & Quadratic & Cubic & Linear & Quadratic & Cubic & Linear & Quadratic & Cubic \\
\hline \multirow[t]{2}{*}{10} & 0.015 & -0.017 & -0.030 & -0.001 & 0.004 & -0.001 & -0.008 & -0.022 & -0.032 \\
\hline & {$[0.02]$} & {$[0.02]$} & [0.04] & {$[0.01]$} & {$[0.01]$} & {$[0.01]$} & {$[0.01]$} & {$[0.02]$} & {$[0.03]$} \\
\hline \multirow[t]{2}{*}{8} & 0.008 & -0.031 & 0.011 & 0.001 & 0.001 & -0.007 & -0.010 & -0.025 & $-0.055 * *$ \\
\hline & {$[0.02]$} & {$[0.03]$} & {$[0.05]$} & {$[0.01]$} & {$[0.01]$} & {$[0.02]$} & {$[0.01]$} & {$[0.02]$} & {$[0.02]$} \\
\hline \multirow[t]{2}{*}{6} & -0.005 & -0.032 & 0.075 & -0.002 & 0.003 & $0.019 * *$ & -0.016 & -0.033 & $-0.107 * * *$ \\
\hline & {$[0.02]$} & {$[0.04]$} & [0.08] & {$[0.01]$} & {$[0.01]$} & {$[0.01]$} & {$[0.01]$} & {$[0.02]$} & {$[0.01]$} \\
\hline
\end{tabular}

Note: This table reports the estimated coefficients from sharp RDDs of the propensity to install the home upgrade given in each panel on an indicator variable for whether the household received the WFP using different polynomials (linear, quadratic and cubic) and bandwidths (6, 8 and 10). Each regression includes the indicated polynomial interactions between the treatment variable and age, log of household income, employment, education qualification dummies, and year of survey fixed effect. See equation 2 for more detail. The estimation sample includes only home owners which household's size is two or lower and the oldest member is male. The number of observations across all outcomes are 3298, 2779, and 2185 for bandwidths 10, 8 and 6, respectively. Standard errors in brackets are adjusted for clustering at age level. $* p<0.10, * * p<0.05, * * * p<0.01$.

Another way to test whether the WFP label is the mechanism behind the reduction in the probability to install renewable energy is to determine whether there are any significant discontinuities in the probability of renewable energy installments at other age levels where receipt of the WFP does not change. If the WFP label is the mechanism, there should not be a discontinuity at other ages within the bandwith. Equation (2) is re-estimated with a treatment variable, $D$, that equals one if the age of the oldest member of the household is 55 , then $56,57,58,59,61,62,63,64$, or 65 in the same qualifying week. This specification will reveal whether a discontinuity in the propensity to install renewable energy exists at these other placebo cutoff ages, where households' eligibility of receiving WFP does not change. Table 9 shows that most estimates of the discontinuity are statistically insignificant and no consistent 
pattern (i.e., some ages that have a statistically significant estimate has one specification that is positive while another is negative). The exception is for a discontinuity at 61 . It is generally negative and statistically significant, though with smaller magnitudes than reported in Table 2. It maybe that households treat the second receipt of the WFP as extra income, in addition to the first, and by their third time the effect of the label has been muted due to past experience. Table 9 results are in line with the WFP being the mechanism that leads to a change in probability to invest in renewable energy, as false cutoffs do not find as strong of a discontinuity as the actual WFP cutoff.

Taken together, these tests offer some support to the claim that the mechanism behind the change in the propensity to install renewable technologies found in Table 2 is due to the WFP and not a result of income effects or a change in age across the two groups. Specifically, this constitutes further evidence that the WFP is seen as price subsidy for energy.

Other possible threats to our identification seem unlikely to compromise the results. First, the comparison induced by our empirical strategy is not among people with substantial different ages. There are 60 years old who are recipients and 60 years old who are not recipients depending on whether they are born before or after the qualifying week in the year in which they turn 60 . So our results cannot be explained by behavior resulting from the simple fact of turning 60 (perhaps a salient age). We would like to emphasise that the limitation of not knowing the precise date of installation should not affect our results. The vast majority of renewables 
Table 9: Discontinuities in the probability of renewable energy installment at different placebo cutoff ages from 55 to 65

\begin{tabular}{|c|c|c|c|c|c|c|c|c|c|}
\hline \multirow[b]{2}{*}{ Placebo ages } & \multicolumn{3}{|c|}{ Bandwidth $=10$} & \multicolumn{3}{|c|}{ Bandwidth $=8$} & \multicolumn{3}{|c|}{ Bandwidth $=6$} \\
\hline & Linear & Quadratic & Cubic & Linear & Quadratic & Cubic & Linear & Quadratic & Cubic \\
\hline \multirow[t]{2}{*}{55} & 0.004 & 0.00 & 0.004 & 0.004 & -0.002 & 0.013 & -0.001 & 0.005 & $0.045 * * *$ \\
\hline & [0.006] & [0.008] & {$[0.010]$} & {$[0.010]$} & [0.010] & {$[0.010]$} & {$[0.008]$} & {$[0.010]$} & [0.008] \\
\hline \multirow[t]{2}{*}{56} & 0.001 & 0.007 & -0.001 & 0.005 & 0.001 & 0.012 & 0.003 & 0.006 & -0.001 \\
\hline & {$[0.006]$} & {$[0.006]$} & [0.008] & {$[0.005]$} & {$[0.005]$} & [0.010] & {$[0.006]$} & {$[0.007]$} & [0.017] \\
\hline \multirow[t]{2}{*}{57} & 0.002 & 0.009 & 0.007 & 0.006 & 0.009 & 0.004 & 0.009 & 0.008 & $-0.022 * *$ \\
\hline & {$[0.005]$} & {$[0.007]$} & {$[0.008]$} & {$[0.005]$} & {$[0.005]$} & {$[0.006]$} & {$[0.006]$} & {$[0.007]$} & {$[0.011]$} \\
\hline \multirow[t]{2}{*}{58} & 0.006 & $0.012 *$ & $0.023 * *$ & 0.004 & $0.023 * *$ & 0.004 & $0.014 * * *$ & 0.012 & 0.004 \\
\hline & [0.004] & {$[0.005]$} & {$[0.010]$} & {$[0.006]$} & [0.008] & [0.006] & [0.005] & {$[0.008]$} & {$[0.010]$} \\
\hline \multirow[t]{2}{*}{59} & -0.001 & 0.009 & 0.003 & 0.001 & 0.009 & -0.006 & 0.008 & -0.003 & 0.012 \\
\hline & {$[0.005]$} & {$[0.007]$} & {$[0.005]$} & [0.006] & {$[0.007]$} & {$[0.005]$} & {$[0.006]$} & [0.004] & {$[0.010]$} \\
\hline \multirow[t]{2}{*}{61} & $-0.012 * *$ & $-0.020 * * *$ & -0.016 & $-0.014 * *$ & $-0.021 * *$ & 0.001 & $-0.018 * * *$ & $-0.014 *$ & $0.015^{*}$ \\
\hline & {$[0.005]$} & [0.007] & {$[0.010]$} & {$[0.005]$} & {$[0.008]$} & {$[0.006]$} & {$[0.005]$} & {$[0.007]$} & {$[0.007]$} \\
\hline \multirow[t]{2}{*}{62} & -0.008 & 0.008 & 0.009 & $-0.012 * *$ & 0.000 & $0.015^{* *} *$ & -0.007 & 0.006 & $0.030 * * *$ \\
\hline & {$[0.006]$} & {$[0.007]$} & {$[0.007]$} & [0.007] & [0.005] & {$[0.006]$} & {$[0.008]$} & {$[0.006]$} & [0.009] \\
\hline \multirow[t]{2}{*}{63} & -0.003 & -0.003 & $0.015^{*}$ & -0.003 & 0.002 & 0.013 & -0.003 & 0.011 & $-0.014 * *$ \\
\hline & [0.006] & {$[0.006]$} & [0.008] & [0.007] & [0.005] & [0.009] & [0.006] & [0.007] & [0.006] \\
\hline \multirow[t]{2}{*}{64} & 0.003 & $0.013^{*}$ & $0.017 * *$ & 0.004 & $0.019 * *$ & 0.009 & 0.009 & $0.014 * *$ & -0.006 \\
\hline & {$[0.006]$} & {$[0.007]$} & {$[0.007]$} & [0.007] & [0.007] & {$[0.007]$} & {$[0.006]$} & {$[0.006]$} & {$[0.008]$} \\
\hline \multirow[t]{2}{*}{65} & 0.006 & 0.007 & -0.005 & 0.006 & 0.006 & $-0.024 * * *$ & 0.012 & -0.012 & $-0.017 * *$ \\
\hline & {$[0.007]$} & {$[0.011]$} & [0.010] & [0.008] & {$[0.012]$} & [0.008] & {$[0.011]$} & {$[0.007]$} & [0.008] \\
\hline
\end{tabular}

Note: This table reports the estimated coefficients from sharp RDDs of the propensity to install renewable technology on an indicator variable for whether the oldest member of the household is either above the age indicated using different polynomials (linear, quadratic and cubic) and bandwidths (6, 8 and 10). Each regression includes year of survey fixed effects, the indicated polynomial interactions between the treatment variable and age, log of household income, employment and education qualification dummies. See equation 2 for more detail. The estimation sample includes only home owners which household's size is two or lower and the oldest member is male. Standard errors in brackets are adjusted for clustering at age level. $* p<0.10$, ** $p<0.05$, *** $p<0.01$.

have been installed in the period covered in this paper. Moreover, given that the methodology adopted revolves around people with similar ages, the existence of this discontinuity should have originated sometime in the past but still driven by the date of birth of the oldest member of the household and used to some years later to determine eligibility criteria to WFP. We find this implausible.

Second, the results cannot be driven by the general shape of the relationship 
between investments and age as we are testing for a discontinuity in that relationship, i.e., it does not matter whether investments are increasing, decreasing or flat with age, as long as there is a jump at the cut off date. Notwithstanding, our analysis shows that investments of this kind are not declining with age. This is perhaps surprising but is in line with Browning et al. (2016) who find that durable good consumption is flat or rising with age using the same dataset. Their paper and our falsification tests show that other home investments are unaffected by this age cut-off, thus reinforcing the idea that the drop in renewable energy investment is not due to a "pure" age effect.

Third, Beatty et al. (2014) analysis show that a number of outcomes, such as changes in expenditures on other household items, are not impacted by receipt of the WFP and that no change in expenditures are found at other cutoff dates. The falsification tests which support their analysis also support ours. Though our paper tests whether a durable good is installed, the repeated cross section nature of the data ensures that each observation is independent.

Other reasons that may discourage investments in the area are not likely to be systematically different before and after the cut off age. For example, the price of solar PV systems generally do not vary based on birth date of homeowner and have been coming down over time (Feldman et al., 2012). The data utilized come from a large government survey where interviewers visit the home and which asks about numerous issues other than energy/environmental issues. As a result, any framing or reporting concerns seem unlikely and we are not aware of different types of questionnaires being administered around the cut off age. There is evidence of solar panels 
being capitalized into housing prices, but no evidence that the value is different by age of homeowner (Dastrup et al., 2012). The data show that $83 \%$ of households in our sample use natural gas to heat their home which is similar to the overall sample average of $82 \%$, thus there is no difference in type of fuel used by household age. The data show no evidence that households are disproportionately likely to move when a member is getting close to the age of 60 , thus anticipation of a change of homes are unlikely driving the results. Previous research finds that receipt of government transfers alters household behavior rather than anticipation of the transfer (Parker et al., 2013 and Attanasio et al., 2012) and the "doughnut hole" estimation given in Table 4 supports this assertion. This seems to confirm that the distortion observed in the renewable market comes down to the receipt of the WFP.

One last analysis is to determine whether the mental accounting effect of the WFP can be nullified by other programs to encourage the use of another energy capital, installation of loft insulation. As the framework described in Section 2, it is expected that the WFP would lead to a decrease in the installation of loft insulation. However, loft insulation is often considered the most cost effective method of improving the energy efficiency of the home and as a result, a number of different programs were available throughout the sample period to provide free loft insulation to households. Some programs were run by the local councils and others were part of the electricity companies required service in programs like the Energy Company Obligations. Indeed, most respondents, who installed loft insulation, report having been given a subsidy to make the installation. This outcome is tested using the EHS 
data, the dataset used in Table 8 . Table 10 shows the estimation results for equation (2) with installation of loft insulation in the last year as an outcome. The first three columns show the estimation including no controls and the second three columns include controls. While the coefficient on the WFP dummy is almost always negative, it is rarely statistically significant. This would imply that it is possible to nullify the effect of the WFP through programs to encourage the use of energy capital.

Table 10: The effect of the WFP on loft insulation installment

\begin{tabular}{lccccccc}
\hline \multirow{2}{*}{ Bandwidth } & \multicolumn{3}{c}{ Without controls } & & \multicolumn{3}{c}{ With controls } \\
\cline { 2 - 4 } \cline { 6 - 8 } \cline { 6 - 8 } & Linear & Quadratic & Cubic & & Linear & Quadratic & Cubic \\
\hline \multirow{4}{*}{8} & 0.004 & -0.002 & -0.033 & & -0.012 & -0.028 & -0.067 \\
& {$[0.013]$} & {$[0.019]$} & {$[0.033]$} & & {$[0.019]$} & {$[0.032]$} & {$[0.051]$} \\
& $\mathrm{N}=3222$ & $\mathrm{~N}=3222$ & $\mathrm{~N}=3222$ & & $\mathrm{~N}=2271$ & $\mathrm{~N}=2271$ & $\mathrm{~N}=2271$ \\
& 0.009 & -0.015 & -0.031 & & -0.010 & -0.038 & -0.079 \\
6 & {$[0.014]$} & {$[0.018]$} & {$[0.033]$} & & {$[0.022]$} & {$[0.035]$} & {$[0.055]$} \\
& $\mathrm{N}=2940$ & $\mathrm{~N}=2940$ & $\mathrm{~N}=2940$ & & $\mathrm{~N}=2060$ & $\mathrm{~N}=2060$ & $\mathrm{~N}=2060$ \\
& 0.03 & -0.023 & $-0.081 * * *$ & & -0.018 & -0.050 & $-0.196^{* * *}$ \\
& {$[0.015]$} & {$[0.027]$} & {$[0.021]$} & & {$[0.025]$} & {$[0.052]$} & {$[0.029]$} \\
& $\mathrm{N}=2308$ & $\mathrm{~N}=2308$ & $\mathrm{~N}=2308$ & & $\mathrm{~N}=1613$ & $\mathrm{~N}=1613$ & $\mathrm{~N}=1613$ \\
\hline
\end{tabular}

Note: This table reports the estimated coefficients from sharp RDDs of the propensity to install loft insulation given in each panel on an indicator variable for whether the household received the WFP using different polynomials (linear, quadratic and cubic) and bandwidths (6, 8 and 10). Each regression includes the indicated polynomial interactions between the treatment variable and age as well as year of survey fixed effect. Controls include log of household income, employment, education qualification dummies, and whether a public subsidy was given for the installation of the loft insulation. See equation 2 for more detail. The estimation sample includes only home owners which household's size is two or lower and the oldest member is male. Standard errors in brackets are adjusted for clustering at age level. $* p<0.10, * * p<0.05, * * * p<0.01$. 


\section{Conclusions}

Do labels attached to unconditional payments affect decision on related goods? Do changes in related goods represent negative unintended consequences? While there is growing evidence building that the label of a cash transfer alters recipients decisions on purchases of the labeled good, the analysis here is the first to answer the question above. The answer has broad implications for nearly every policy. Many of the most common transfers have labels which suggest a use for the transfer.

This paper tests whether households substitute away from renewable energy technologies, which are more energy efficient, when receiving a cash transfer, the WFP, which primes them to purchase fuel. Using a simple model of household production of energy services which can be met by fuel or more efficient capital, it is shown that when households receive a cash transfer labeled with the word fuel it will lead to an increase in the amount of fuel used Beatty et al. (2014) but have an ambiguous impact on whether more energy capital is used.

This theoretical result is confirmed when taken to data. Identification of the WFP treatment is based on the sharp eligibility criteria of the WFP, confirmation that other explanatory variables are continuous around the discontinuity, and numerous falsification tests. In other words, the effect of the WFP is for households to choose energy sources which pollute more. Results find that the likelihood of investing in renewable technologies at home decline by 1.2 percentage points after the receipt of the WFP. This is the estimated value from linear models with bandwidth of 10 , 
which statistical tests indicate as optimal. The range of the estimated values go from 1 to 3.5 percentage points. The results are not only statistically significant, but also economically relevant. Considering the universality of the transfer, this is a considerable number. Our models predict that approximately $69 \%$ of households whose oldest member turns 60 would have invested in renewable energy but refrain to do so after receiving the WFP. ${ }^{31}$

Given that renewable technologies are one way to ensure that a household can afford to heat its home, these results imply that the label of the transfer nudges households towards a less socially efficient outcome in which a desired amount of heating is achieved with more pollution at the expense of cleaner renewable energy installments. Ultimately, the transfer is counterproductive to the ultimate goal of the policy as it moves households away from one way to achieve the goal itself. Additionally, concerns over greenhouse gas emissions, energy security, and the competitiveness of the UK economy, have led to the recent implementation of a number of renewable energy policies. The evidence given here suggests that the effectiveness of renewable policies is being hampered by the WFP label. Our analysis shows that this distortion is more precisely estimated for richer households, which are not in need of support. This reinforces the argument that a more desirable outcome, one in which energy policy objective are in harmony with public health ones, is possible. This issue may be straightforward to remedy; rename the transfer to something that primes the house-

\footnotetext{
${ }^{31}$ This number is the difference in the predicted portion of households who would have installed in the absence of the WFP vs household who installed. It is obtained by running the linear model with controls and bandwidth=10 in Table 2 (see also equation 2) and then (a) computing the linear predictions at the cutoff when $D=1$ (b) computing it when $D=0$ and then taking the difference.
} 
hold to think about energy efficiency or renewables, such as the Winter Renewable Energy Payment. 


\section{References}

Abeler, J. and Marklein, F. (2017). Fungibility, labels, and consumption, 15(1): 99127.

Allcott, H. (2011). Social norms and energy conservation, Journal of Public Economics 95(9): 1082-1095.

Allcott, H. and Mullainathan, S. (2010). Behavior and energy policy, Science 327(5970): $1204-1205$.

Allcott, H. and Rogers, T. (2014). The short-run and long-run effects of behavioral interventions: Experimental evidence from energy conservation, American Economic Review 104(10): 3003-3037.

Andor, M., Frondel, M. and Vance., C. (2017). German's energiewende: A tale of increasing costs and decreasing willingness-to-pay, The Energy Journal 38: 211228.

Angrist, J. D. and Pischke, J. S. (2009). Mostly Harmless Econometrics: An Empiricist's Companion, Princeton University Press.

Attanasio, O. P., Meghir, C. and Santiago, A. (2012). Education choices in mexico: Using a structural model and a randomized experiment to evaluate progresa, The Review of Economic Studies 79(1): 37-66.

Ayres, I., Raseman, S. and Shih, A. (2013). Evidence from two large field experi- 
ments that peer comparison feedback can reduce residential energy usage, Journal of Law, Economics, and Organization 29(5): 992-1022.

Barreca, A., Guldi, M., Lino, J. and Waddell, G. (2011). Saving babies? revisiting the effect of very low birth weight classification, Quarterly Journal of Economics 126(4): 2117-2123.

Beatty, T., Blow, L., Crossley, T. F. and O’Dea, C. (2014). Cash by any other name? evidence on labelling from the uk winter fuel payment, Journal of Public Economics 118: 86-96.

Beatty, T. and Tuttle, C. (2015). Expenditure response to increases in in-kind transfers: Evidence from the supplemental nutrition assistance program, American Journal of Agricultural Economics (forthcoming).

Benhassine, N., Devoto, F., Duflo, E., Dupas, P. and Pouliquen, V. (2015). Turning a shove into a nudge? a "labeled cash transfer" for education, American Economic Journal: Economic Policy 7(3): 86-125.

Blow, L., Walker, I. and Zhu, Y. (2012). Who benefits from child benefit?, Economic Inquiry 50(1): 153-170.

Blundell, R., Bozio, A. and Laroque, G. (2011). Labor supply and the intensive margin, American Economic Review 11(3): 482-486.

Breman, A. (2011). Give more tomorrow: Two field experiments on altruism and intertemporal choice, Journal of Public Economics 95(11-12): 1349 - 1357. 
Brewer, M., Crossley, T. and Joyce, R. (2013). Inference with difference-indifferences revisited, IZA Discussion Papers 7742, Institute for the Study of Labor (IZA).

URL: http://EconPapers.repec.org/RePEc:iza:izadps:dp7742

Brown, Z., Johnstone, N., Haščič, I., Vong, L. and Barascud, F. (2013). Testing the effect of defaults on the thermostat settings of oecd employees, Energy Economics 39: $128-134$.

Browning, M., Crossley, T. and Melanie, L. (2016). Durable purchases over the later life cycle, Oxford Bulletin of Economics and Statistics 78(2): 145-169.

Cameron, A. C., Gelbach, J. B. and Miller, D. L. (2008). Bootstrap-based improvements for inference with clustered errors, The Review of Economics and Statistics 90(3): 414-427.

Chetty, R., Friedman, J. N., Leth-Petersen, S., Nielsen, T. and Olsen, T. (2012). Active vs. passive decisions and crowdout in retirement savings accounts: Evidence from denmark, National Bureau of Economic Research Working Paper No. 18565.

Chetty, R., Looney, A. and Kroft, K. (2009). Salience and taxation: Theory and evidence, American Economic Review 99(4): 1145-77.

Cialdini, R. B. (2003). Crafting normative messages to protect the environment, Current Directions in Psychological Science 12(4): 105-109. 
Dastrup, S., Graff Zivin, J., Costa, D. L. and Kahn, M. E. (2012). Understanding the solar home price premium: electricity generation and "green" social status, European Economic Review 56(5): 961-973.

DiNardo, J. and Lee, D. S. (2011). Program evaluation and research designs, Vol. 4, Part A of Handbook of Labor Economics, Elsevier, pp. 463 - 536.

Duflo, E., Kremer, M. and Robinson, J. (2011). Nudging farmers to use fertilizer: Theory and experimental evidence from kenya.", American Economic Review 101(6): 2350-90.

Feldman, D., Barbose, G., Margolis, R., Wiser, R., Darghouth, N. and Goodrich, A. (2012). Photovoltaic pricing trends: Historical, recent, and near-term projections, Lawrence Berkeley National Laboratory Technical Report No. DOE/GO-1020123839.

Ferraro, P. J. and Price, M. K. (2013). Using nonpecuniary strategies to influence behavior: evidence from a large-scale field experiment, Review of Economics and Statistics 95(1): 64-73.

Fischer, C. (2008). Feedback on household electricity consumption: a tool for saving energy?, Energy efficiency 1(1): 79-104.

Gelman, A. and Imbens, G. (2014). Why high-order polynomials should not be used in regression discontinuity designs, Technical Report 20405, National Bureau of Economic Research Working Paper No. 
Giné, X., Karlan, D. and Zinman, J. (2010). Put your money where your butt is: A commitment contract for smoking cessation, American Economic Journal: Applied Economics 2(4): 213-35.

Hahn, J., Todd, P. and van der Klaauw, W. (2001). Identification and estimation of treatment effects with a regression-discontinuity design, Econometrica 69(1): 201-209.

Hastings, J. and Shapiro, J. (2013). Fungibility and consumer choice: Evidence from commodity price shocks, 128(4): 1449-1498.

Homonoff, T. A. (2013). Can small incentives have large effects? the impact of taxes versus bonuses on disposable bag use, Industrial Relations Section, Princeton University Working Paper No. 575.

Imbens, G. and Kalyanaraman, K. (2012). Optimal bandwidth choice for the regression discontinuity estimator, The Review of Economic Studies 79(3): 933 959.

Imbens, G. and Lemieux, T. (2008). Regression discontinuity designs: A guide to practice, Journal of Econometrics 142(2): 615-635.

Imbens, G. and Wooldridge, J. (2008). Recent developments in the econometrics of program evaluation, National Bureau of Economic Research Working Paper No. 14251. 
Jaraite, J., Karimu, A. and Kazukauskas, A. (2017). Policy-induced expansion of solar and wind power capacity: Economic growth and employment in eu countries, The Energy Journal 38(5): 197-222.

Jessoe, K. and Rapson, D. (2014). Knowledge is (less) power: Experimental evidence from residential energy use, American Economic Review 4(104): 14171438.

Kallbekken, S., Sælen, H. and Hermansen, E. A. (2013). Bridging the energy efficiency gap: A field experiment on lifetime energy costs and household appliances, Journal of Consumer Policy 36(1): 1-16.

Kooreman, P. (2000). The labeling effect of a child benefit system, The American Economic Review 90(3): 571-583.

La Nauze, A. (2017). Power from the people: Rooftop solar and a downward-sloping supply of electricity, Technical report, University of Pittsburgh Mimeo.

Lee, D. S. and Lemieux, T. (2010). Regression discontinuity designs in economics, Journal of Economic Literature 48(2): 281-355.

Madrian, B. C. and Shea, D. F. (2001). The power of suggestion: Inertia in 401 (k) participation and savings behavior, The Quarterly Journal of Economics 116(4): 1149-1187.

Mansi, B. and Scott, M. (2015). Bootwildct. available at http://www.ifs.org.uk/publications/6231. 
Mathios, A. D. (2000). The impact of mandatory disclosure laws on product choices: An analysis of the salad dressing market*, The Journal of Law and Economics 43(2): 651-678.

Newell, R. G. and Siikamäki, J. V. (2014). Nudging energy efficiency behavior: The role of information labels, Journal of the Association of Environmental and Resource Economics 1(4): 555-598.

Parker, J., Souleles, N., Johnson, D. and McClelland, R. (2013). Consumer spending and the economic stimulus paymetns of 2008, American Economic Review 103(6): 2530-2553.

Reiss, P. C. and White, M. W. (2008). What changes energy consumption? prices and public pressures, The RAND Journal of Economics 39(3): 636-663.

Schultz, P. W., Nolan, J. M., Cialdini, R. B., Goldstein, N. J. and Griskevicius, V. (2007). The constructive, destructive, and reconstructive power of social norms, Psychological science 18(5): 429-434.

Schultz, W. P., Khazian, A. M. and Zaleski, A. C. (2008). Using normative social influence to promote conservation among hotel guests, Social influence 3(1): 423.

Swartz, J. J., Braxton, D. and Viera, A. J. (2011). Calorie menu labeling on quickservice restaurant menus: an updated systematic review of the literature, Int $J$ Behav Nutr Phys Act 8(8): 135. 
Thaler, R. H. (1990). Anomalies: Saving, fungibility, and mental accounts, The Journal of Economic Perspectives 4(1): 193-205.

Thaler, R. H. (2004). Mental accounting matters, Russell Sage Foundation. Princeton, NJ: Princeton University Press.

Thaler, R. H. and Benartzi, S. (2004). Save more tomorrow ${ }^{\mathrm{TM}}$ : Using behavioral economics to increase employee saving, Journal of Political Economy 112(S1): S164-S187.

Van der Klaauw, W. (2008). Regression-discontinuity analysis: a survey of recent developments in economics, Labour 22(2): 219-245. 


\section{Appendix A}

Table A.1: Optimal polynomial order selection using the Akaike Information Criterion (AIC)

\begin{tabular}{lccccccc}
\hline \multirow{2}{*}{ Bandwidth } & \multicolumn{3}{c}{ Without controls } & & \multicolumn{3}{c}{ With controls } \\
\cline { 2 - 4 } \cline { 6 - 8 } \cline { 6 - 8 } & Linear & Quadratic & Cubic & & Linear & Quadratic & Cubic \\
\hline 10 & -5438.88 & -5437.30 & -5435.09 & & -5443.14 & -5441.36 & -5439.45 \\
8 & -5750.59 & -5748.85 & -5748.11 & & -4891.44 & -4890.16 & -4891.94 \\
6 & -4889.58 & -4888.13 & -4887.79 & -4891.44 & -4890.16 & -4891.94 \\
\hline
\end{tabular}

Note : This table reports the AIC statistics computed for each model presented in Table 2. The optimal polynomial order is the one with minimum AIC value.

Table A.2: The effect of the WFP on renewable energy installment using wild clusterbootstrap (Cameron et al., 2008)

\begin{tabular}{|c|c|c|c|c|c|c|}
\hline \multirow{2}{*}{ Bandwidth } & \multicolumn{3}{|c|}{ Without controls } & \multicolumn{3}{|c|}{ With controls } \\
\hline & Linear & Quadratic & Cubic & Linear & Quadratic & Cubic \\
\hline 10 & $\begin{array}{c}-0.012 * * \\
(0.04)\end{array}$ & $\begin{array}{c}-0.013 * \\
(0.10)\end{array}$ & $\begin{array}{c}-0.028 * * * \\
(0.00)\end{array}$ & $\begin{array}{c}-0.012 * \\
(0.04)\end{array}$ & $\begin{array}{c}-0.014 * \\
(0.09)\end{array}$ & $\begin{array}{c}-0.030 * * * \\
(0.00)\end{array}$ \\
\hline & $N=3656$ & $\mathrm{~N}=3656$ & $\mathrm{~N}=3656$ & $N=3656$ & $\mathrm{~N}=3656$ & $\mathrm{~N}=3656$ \\
\hline 8 & $\begin{array}{l}-0.009 \\
(0.24)\end{array}$ & $\begin{array}{c}-0.023 * * * \\
(0.00)\end{array}$ & $\begin{array}{c}-0.023 * * * \\
(0.00)\end{array}$ & $\begin{array}{l}-0.009 \\
(0.21)\end{array}$ & $\begin{array}{c}-0.024 * * * \\
(0.00)\end{array}$ & $\begin{array}{c}-0.025 * * * \\
(0.00)\end{array}$ \\
\hline & $\mathrm{N}=3074$ & $\mathrm{~N}=3074$ & $\mathrm{~N}=3074$ & $\mathrm{~N}=3074$ & $\mathrm{~N}=3074$ & $\mathrm{~N}=3074$ \\
\hline 6 & $\begin{array}{c}-0.018^{* *} \\
(0.02)\end{array}$ & $\begin{array}{c}-0.015^{* * *} \\
(0.00)\end{array}$ & $\begin{array}{c}-0.035^{* * *} \\
(0.00)\end{array}$ & $\begin{array}{c}-0.018^{* *} \\
(0.00)\end{array}$ & $\begin{array}{c}-0.016 * * * \\
(0.00)\end{array}$ & $\begin{array}{c}-0.036 * * * \\
(0.00)\end{array}$ \\
\hline & $\mathrm{N}=2411$ & $\mathrm{~N}=2411$ & $\mathrm{~N}=2411$ & $\mathrm{~N}=2411$ & $\mathrm{~N}=2411$ & $\mathrm{~N}=2411$ \\
\hline
\end{tabular}

Note: This table estimates equation 2 in table 2 using wild cluster bootstrap percentile t-procedure, imposing the null hypothesis for each coefficient, as shown in (Cameron et al., 2008). $P$-values obtained from bootstrapped t-stats are shown in parenthesis. 
Table A.3: The effect of WFP on energy renewable instalments - Logit regressions

\begin{tabular}{|c|c|c|c|c|c|c|}
\hline \multirow{2}{*}{ Bandwidth } & \multicolumn{3}{|c|}{ Without controls } & \multicolumn{3}{|c|}{ With controls } \\
\hline & Linear & Quadratic & Cubic & Linear & Quadratic & Cubic \\
\hline 10 & $\begin{array}{c}-0.015 * * * \\
{[0.005]} \\
\mathrm{N}=3656\end{array}$ & $\begin{array}{c}-0.014 * \\
{[0.007]} \\
\mathrm{N}=3656\end{array}$ & $\begin{array}{c}-0.032 * * * \\
{[0.008]} \\
\mathrm{N}=3656\end{array}$ & $\begin{array}{c}-0.015 * * * \\
{[0.005]} \\
\mathrm{N}=3656\end{array}$ & $\begin{array}{c}-0.016 * * \\
{[0.008]} \\
N=3656\end{array}$ & $\begin{array}{c}-0.034 * * * \\
{[0.008]} \\
\mathrm{N}=3656\end{array}$ \\
\hline 8 & $\begin{array}{c}-0.009 \\
{[0.006]} \\
\mathrm{N}=3074\end{array}$ & $\begin{array}{c}-0.021 * * * \\
{[0.007]} \\
\mathrm{N}=3074\end{array}$ & $\begin{array}{c}-0.017 * * \\
{[0.008]} \\
N=3074\end{array}$ & $\begin{array}{c}-0.010 \\
{[0.006]} \\
\mathrm{N}=3074\end{array}$ & $\begin{array}{c}-0.022 * * * \\
{[0.007]} \\
\mathrm{N}=3074\end{array}$ & $\begin{array}{c}-0.019 * * \\
{[0.008]} \\
N=3074\end{array}$ \\
\hline 6 & $\begin{array}{c}-0.019 * * * \\
{[0.007]} \\
\mathrm{N}=2411\end{array}$ & $\begin{array}{c}-0.009 * * \\
{[0.004]} \\
\mathrm{N}=2411\end{array}$ & $\begin{array}{c}-0.029 * * * \\
{[0.010]} \\
\mathrm{N}=2411\end{array}$ & $\begin{array}{c}-0.020 * * \\
{[0.008]} \\
\mathrm{N}=2411\end{array}$ & $\begin{array}{c}-0.011 * * * \\
{[0.004]} \\
\mathrm{N}=2411\end{array}$ & $\begin{array}{c}-0.033 * * * \\
{[0.008]} \\
\mathrm{N}=2411\end{array}$ \\
\hline
\end{tabular}

Note: This table reports the marginal effects from sharp RDDs of the propensity to install renewable technology on an indicator variable for whether the household received the WFP using different polynomials (linear, quadratic and cubic) and bandwidths (6,8 and 10) estimated using logit regressions. Each regression includes year of survey fixed effects and a series of interactions between the treatment variable and normalized age. The last three columns include also log of household income, employment and education qualification dummies. See equation 2 for more detail. The estimation sample includes only home owners whose household size is two or lower and the oldest member is male. Standard errors in brackets are adjusted for clustering at age level. * $p<0.10$, ** $p<0.05$, *** $p<0.01$. 
Table A.4: The effect of WFP on energy renewable instalments - Excluding 2011

\begin{tabular}{|c|c|c|c|c|c|c|}
\hline \multirow{2}{*}{ Bandwidth } & \multicolumn{3}{|c|}{ Without controls } & \multicolumn{3}{|c|}{ With controls } \\
\hline & Linear & Quadratic & Cubic & Linear & Quadratic & Cubic \\
\hline \multirow[t]{3}{*}{10} & $-0.012 * *$ & $-0.013 *$ & $-0.028 * * *$ & $-0.012 *$ & $-0.014 *$ & $-0.030 * * *$ \\
\hline & {$[0.006]$} & [0.007] & [0.004] & [0.006] & [0.007] & [0.004] \\
\hline & $N=3656$ & $N=3656$ & $N=3656$ & $N=3656$ & $N=3656$ & $N=3656$ \\
\hline \multirow[t]{3}{*}{8} & -0.009 & $-0.023 * * *$ & $-0.023 * * *$ & -0.009 & $-0.024 * * *$ & $-0.025 * * *$ \\
\hline & {$[0.006]$} & {$[0.005]$} & {$[0.006]$} & {$[0.007]$} & {$[0.006]$} & [0.006] \\
\hline & $\mathrm{N}=3074$ & $\mathrm{~N}=3074$ & $\mathrm{~N}=3074$ & $N=3074$ & $\mathrm{~N}=3074$ & $N=3074$ \\
\hline \multirow[t]{3}{*}{6} & $-0.018 * *$ & $-0.015 * * *$ & $-0.035 * * *$ & $-0.018 * *$ & $-0.016 * * *$ & $-0.036 * * *$ \\
\hline & {$[0.006]$} & {$[0.004]$} & {$[0.005]$} & {$[0.007]$} & [0.004] & {$[0.005]$} \\
\hline & $\mathrm{N}=2411$ & $\mathrm{~N}=2411$ & $\mathrm{~N}=2411$ & $\mathrm{~N}=2411$ & $\mathrm{~N}=2411$ & $\mathrm{~N}=2411$ \\
\hline
\end{tabular}

Note: This table reports the marginal effects from sharp RDDs of the propensity to install renewable technology on an indicator variable for whether the household received the WFP using different polynomials (linear, quadratic and cubic) and bandwidths (6, 8 and 10). Each regression includes year of survey fixed effects (excluding year 2011) and a series of interactions between the treatment variable and normalized age. The last three columns include also log of household income, employment and education qualification dummies. See equation 2 for more detail. The estimation sample includes only home owners whose household size is two or lower and the oldest member is male. Standard errors in brackets are adjusted for clustering at age level. * $p<0.10, * * p<0.05, * * * p<0.01$. 


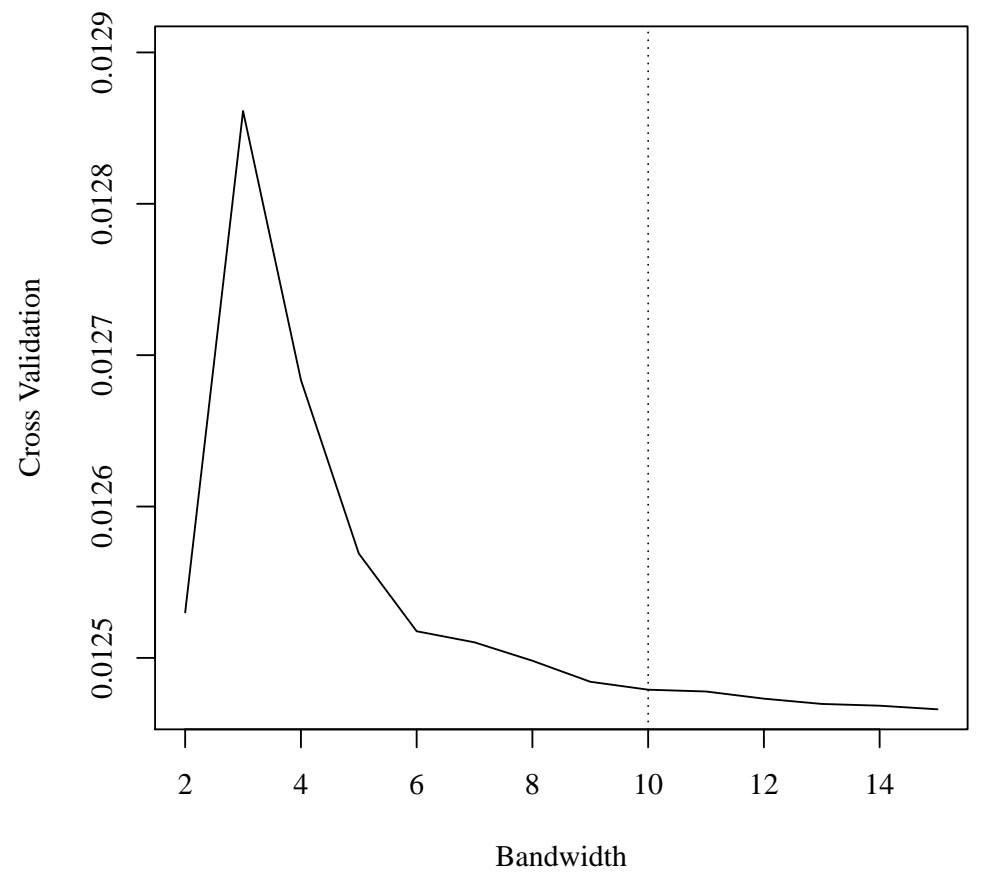

Figure A.1: Plotting cross validation against bandwidth for choosing the optimal bandwidth in Table 2 